\title{
Severity of $E$. coli mastitis is mainly determined by cow factors
}

\author{
Christian BuRVENICH*, Valérie VAn MERRIS, Jalil MEHRZAD, \\ Araceli DIEZ-FraILE, Luc DUCHATEAU
}

Mammary gland and Mastitis Research Centre, Department of Physiology, Biochemistry and Biometrics, Faculty of Veterinary Medicine, Ghent University, Salisburylaan 133, 9820 Merelbeke, Belgium

(Received 4 February 2003; accepted 29 April 2003)

\begin{abstract}
Intramammary infections of dairy cows with Gram-positive bacteria such as Staphylococcus aureus (major cause of mastitis) have received a lot of attention because of their major economic impact on the dairy farm through production losses induced by an increase in somatic cell count. Management strategies, including greater awareness for efficient milking and hygienic measures, have limited the spread of Gram-positive bacteria and resulted in a significant decrease of proportion of $S$. aureus isolates and subclinical mastitis worldwide. Other organisms such as coliform subspecies and Streptococcus uberis, both environmental bacteria that cause clinical mastitis, have received less attention. Escherichia coli causes inflammation of the mammary gland in dairy cows around parturition and during early lactation with striking local and sometimes severe systemic clinical symptoms. This disease affects many high producing cows in dairy herds and may cause several cases of death per year in the most severe cases. It is well known that bacterial, cow and environmental factors are interdependent and influence mastitis susceptibility. Many studies, executed during the last decade, indicate that the severity of $E$. coli mastitis is mainly determined by cow factors rather than by $E$. coli pathogenicity. During $E$. coli mastitis, the host defense status is a cardinal factor determining the outcome of the disease. Today, we know that the neutrophil is a key factor in the cows' defense against intramammary infection with E. coli. Effective elimination of the pathogen by neutrophils is important for the resolution of infection and the outcome of $E$. coli mastitis. This review is a compilation of some major findings over the last 15 years concerning mainly host factors that modulate and influence neutrophil function and the mammary inflammatory reaction. The individual chapters address: virulence factors of $E$. coli strains, how neutrophils kill $E$. coli, connection between endotoxins, tumor necrosis factor- $\alpha$ and nitric oxide, severity classification of $E$. coli mastitis, lifespan of neutrophils, host factors that influence severity, tissue damage and production loss.
\end{abstract}

dairy cow / Escherichia coli mastitis / neutrophil / severity

Table of contents

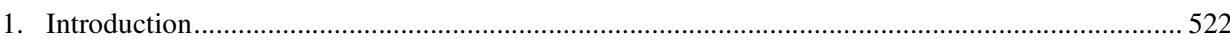

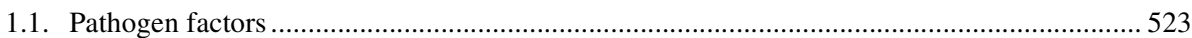

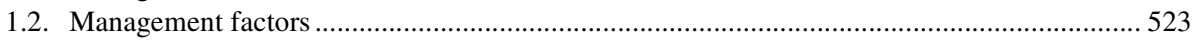

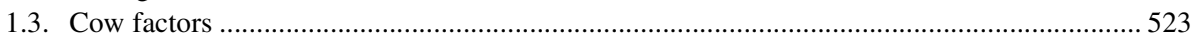

* Corresponding author: christian.burvenich@ugent.be 


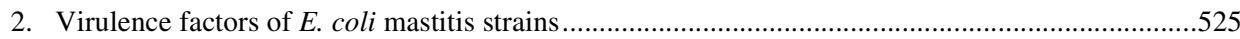

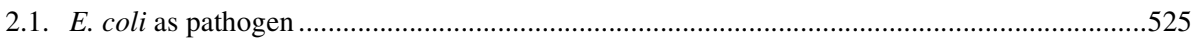

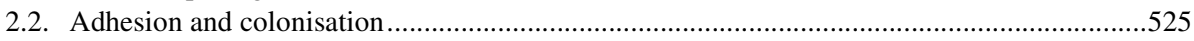

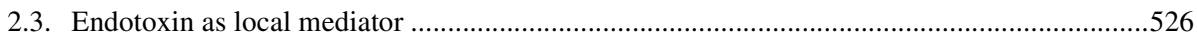

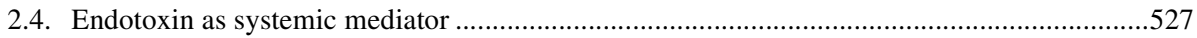

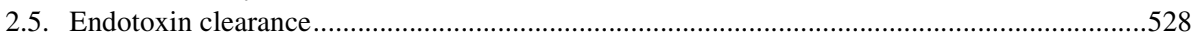

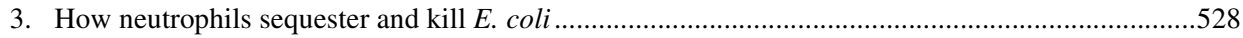

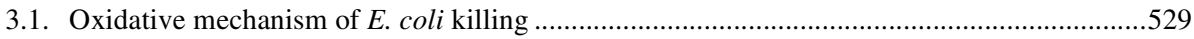

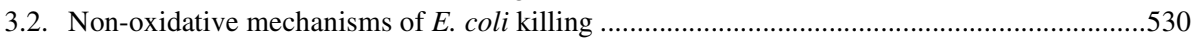

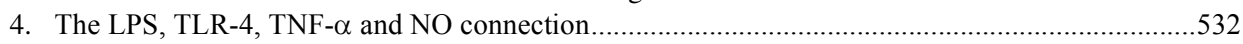

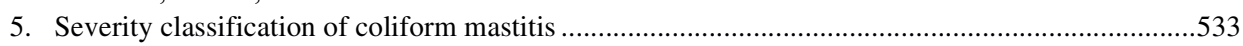

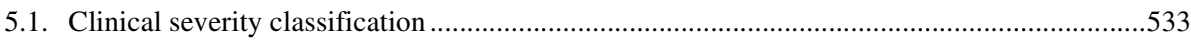

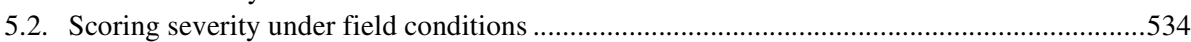

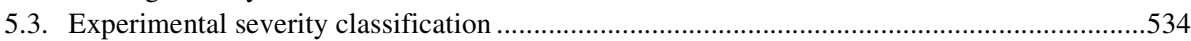

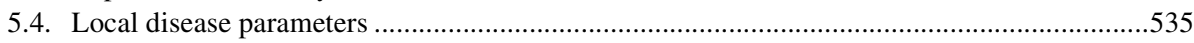

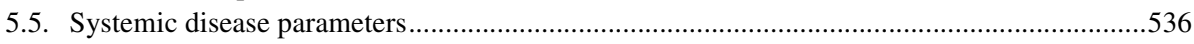

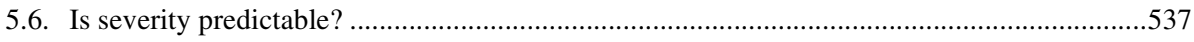

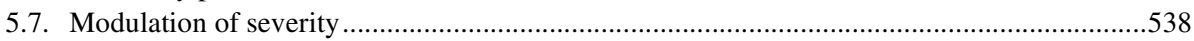

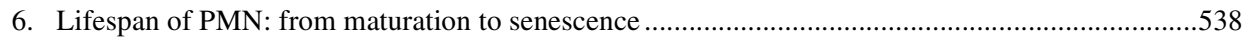

6.1. Proliferation, differentiation and maturation of PMN .......................................................538

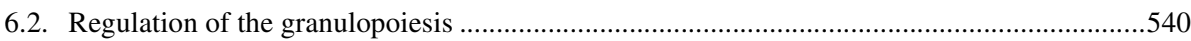

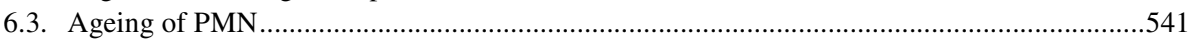

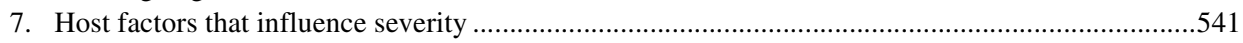

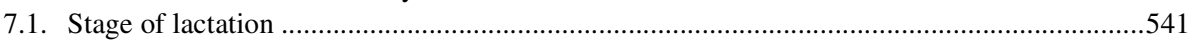

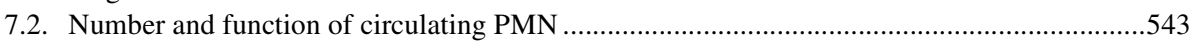

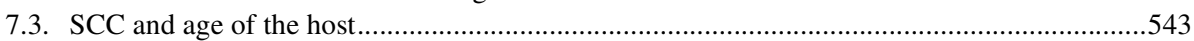

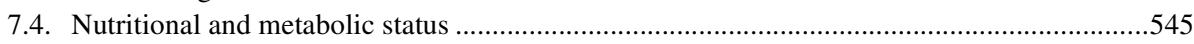

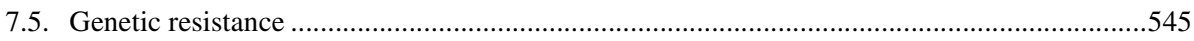

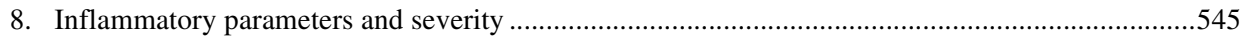

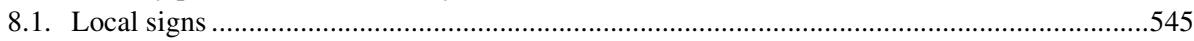

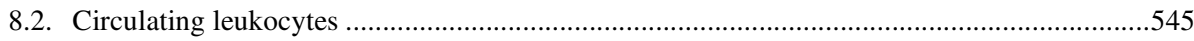

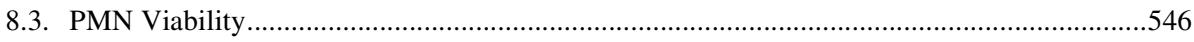

9. Tissue damage and production loss during E. coli mastitis.........................................................547

9.1. Pathologic findings during E. coli mastitis ......................................................................547

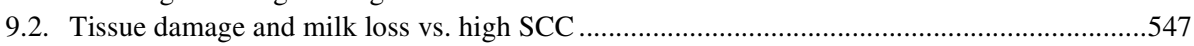

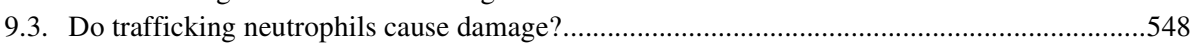

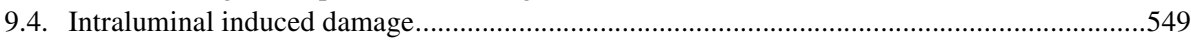

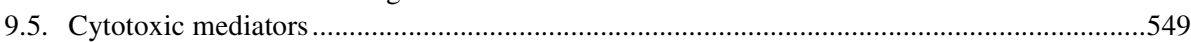

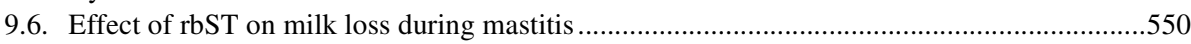

9.7. Lesions in rare cases of atypical E. coli mastitis .............................................................552

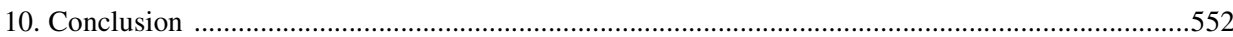

\section{INTRODUCTION}

Escherichia coli causes infection and inflammation of the mammary gland in dairy cows mainly around parturition and during early lactation with striking local and sometimes severe systemic clinical symptoms. This so-called environmental type of mastitis may affect productivity of high producing cows in dairy herds. It may also cause several deaths per year in the most severe cases. E. coli invades the udder through the teat canal where it grows and initiates a prompt inflammatory reaction, 
with increasing numbers of neutrophils appearing. This neutrophil infiltration is one of the first steps of the inflammatory reaction because they have to prevent escape and multiplication of the pathogens.

It is well known that bacterial, environmental or management, and cow factors may change susceptibility for mastitis. These factors are interdependent and especially the relative impact of each factor depends on the type of pathogen [234].

\subsection{Pathogen factors}

The pathogenesis of coliform mastitis is completely different from diseases such as colibacillosis in calves and pigs. For example, it is well known that in so-called enterotoxigenic E. coli (ETEC) strains, the colonisation of intestinal mucosa is related to the expression of several different proteinaceous surface structures, i.e. colonisation factors, which recognise specific receptors on the intestinal epithelial surface $[47,206]$. The pathogenicity in these animals mainly depends on expression of particular virulence factors. For coliform mastitis this is not the case, and it is generally accepted that the type of E. coli strain does not play a major role in the severity classification [24]. A non-specific but potent factor that is important during the pathogenesis of E. coli is the endotoxin or lipopolysaccharide (LPS) [64]. At the one hand it induces defence mechanisms and at the other hand it is a toxic compound. Pathophysiological effects of endotoxins in ruminants are dose-dependent and elicit a variety of metabolic and clinical signs [143, 144].

\subsection{Management factors}

Management factors that influence the cow's condition during late pregnancy, mainly with respect to energy, in order to achieve a fast and high peak of milk production, might be the cause of metabolically immunocompromised cows that have lower resistance to stress induced by partu- rition and early lactation. Once adapted, i.e. after peak lactation, it seems that cows are less susceptible for environmental pathogens.

The organised control of bulk and cow milk samples by specialised milk quality centres has resulted, especially in Europe, in a significant reduction in normal somatic cell count (SCC). There is a tendency to believe that low milk SCC fails to protect the udder from environmental pathogens (reviewed by [227]). This finding is mainly based on epidemiological data and there are only a few experimental data that can confirm these findings (e.g. [210]). Finally, higher stock densities have resulted in a greater pasture contamination with easier access for environmental pathogens to the udder through their open teats during calving and early lactation. Management factors fall beyond the scope of this review.

\subsection{Cow factors}

The ability of neutrophils to sequester and kill the pathogens is a critical step in the defence reaction against $E$. coli. The progress of the inflammatory reaction is determined by a constitutive balance between forces opposing pathogen growth and production of virulent factors, and the forces favouring it. Neutrophils are very beneficial to the udder following $E$. coli infection, and form the most important body defence mechanism. It is essential that they arrive in the lumen of the udder promptly if they are to be totally effective. Since 1990, numerous reviews have been written summarising and updating the progress toward the understanding of the mechanisms of the neutrophil response into udder tissue and cistern during E. coli mastitis [31-33, 177, 179]. More recently, excellent reviews have been published in connection with the immune mechanisms in the mammary gland $[119,180,220]$. It is well recognised that clinical E. coli mastitis cases occurring during established lactation show a minimum of systemic signs (such as fever, discomfort, temporary milk 
production drop, etc.). Clinical signs are moderate, subside very rapidly and the animal cures itself. Under these conditions, the inflammatory reaction has to be considered as a $100 \%$ physiological reaction. It seems that at parturition and during early lactation, high producing cows are more sensitive for infection with common environmental pathogens such as E. coli. Many factors may have contributed to this phenomenon but the animals' physiological pre-infection status also influences the outcome of coliform mastitis.

From many studies performed during the last 15 years, it is evident that the severity of bovine E. coli mastitis is mainly determined by cow factors rather than by the pathogenicity of the invading pathogen. During coliform mastitis, the host defence status is a cardinal factor determining the pathogenicity and the clinical outcome of this disease, depending on its interaction with the pathogen and its LPS. In this review some aspects will be covered of LPS in relation with severity of coliform mastitis.

Initiation and resolution of inflammation is controlled by a complex network of biological substances that belong to the homeostatic armamentarium of the host. Since 1990 a long list of original papers, dealing with the impact of the physiology of the cow (parturition, lactation stage, age, metabolism, pro- and anti-inflammatory endogenous substances, growth factors, platelet activating factor, etc.) on the pathogenesis of mastitis, have been published. Each imbalance in initiation, tuning and resolution results in host and/or tissue damage and severe prognosis of the disease.

As a consequence of neutrophil infiltration into the invaded area of the mammary gland, changes in blood cell composition occur, due to bone marrow stimulation and alteration of the normal venular equilibrium that controls attachment, rolling and diapedesis. Next to the changes in the cellular blood picture, composition of extracellular water (internal sea; [37]) also changes. The concept of a well-balanced inflammatory response where pro- and anti-inflammatory local mediators, such as cytokines, regulate the outcome of the inflammatory process, is also applicable to systemic factors [34]. The inflammatory reaction is a rapid and mainly a non-specific defence that is accompanied by the release and/or "de novo synthesis" of specific and non-specific molecules, such as systemic and tissue hormones and (poly)peptides. The metabolism of the animal is also changed. Hormones, metabolites and acute phase proteins, may influence the outcome of mastitis.

Curing (the final goal of the inflammatory reaction) of the mammary gland is only successful if minimal host and tissue damage occurs. Therefore, the inflammatory reaction has to be fast, short lasting and regulated. After elimination of the invading pathogens, neutrophil reaction subsides to promote a predominant mononuclear cell picture. Macrophages do not only replace neutrophils but also actively participate in their removal [181]. This last step represents the resolution of the inflammatory reaction. Neutrophil infiltration and resolution during $E$. coli mastitis are necessary to reset the composition of the "internal sea" towards the pre-infection status of the organism and this is accompanied by specific and non-specific systemic events. This is in agreement with the general concepts in physiology [37].

This chapter is a compilation of some major findings over the last 15 years concerning mainly host factors that modulate and influence neutrophil function and the inflammatory reaction of the lactating cow. The individual chapters are dealing with virulence factors of $E$. coli mastitis strains, how neutrophils sequester and kill E. coli, the connection between endotoxins, tumor necrosis factor- $\alpha$ (TNF- $\alpha$ ) and nitric oxide (NO), severity classification of coliform mastitis, lifespan of neutrophils (from maturation to senescence), host factors that 
influence severity, tissue damage and production loss.

\section{VIRULENCE FACTORS OF E. COLI MASTITIS STRAINS}

\section{1. $E$. coli as pathogen}

E. coli is a member of the family of Enterobacteriaceae. Of primary importance is their ability for fermentation of lactose. Over 700 antigenic types or serotypes of $E$. coli have been recognised based on $\mathrm{O}$, $\mathrm{H}$, and $\mathrm{K}$ antigens. Two classes of coliforms have to be distinguished: strains that are harmless (non-pathogenic strains) and strains that cause a wide variety of typical clinical infections (pathogenic strains, [47]). Millions of non-pathogenic E. coli bacteria are living in the normal intestinal microflora of both humans and animals. E. coli adheres to the mucus overlaying the large intestine where they constitute a useful microbial barrier because of their antagonism to pathogenic bacteria. E. coli is massively excreted with the faeces in the environment. E. coli is ubiquitous in the cow's environment. It is obvious that challenge of E. coli udder infection will remain so long as cows produce faeces [112]. They behave as opportunistic pathogens. There has been a substantial rise in the incidence of E. coli mastitis since 1960 and it is accepted to be the most common cause of fatal mastitis [163]. In contrast to the enteropathogenic and bacteraemic strains, which are caused by a relatively low number of E. coli serotypes [47], the isolates from bovine coliform mastitis belong to a very large number of serological groups. E. coli serotypes in mastitic milk are similar to the faecal isolates. There are a very large number of $E$. coli serotypes as classified by surface antigens but the inner layer of the cell wall is common to all serotypes of E. coli and Enterobacteriaceae in general [65].

\subsection{Adhesion and colonisation}

Following experimental intramammary (I.M.) challenge with E. coli, attachment to mammary epithelium was not observed [136]. Electron microscopic research on the pathogenesis of coliform mastitis never revealed attachment of bacteria to the epithelium [24]. Attachment of E. coli to mammary epithelial cells seems not to be essential for the pathogenesis of clinical coliform mastitis [76, 175]. Most of mastitis pathogen adhesion studies have been performed with cell cultures for which several models have been described. Lammers et al. [132] used E. coli strain HB101 as negative control to test adhesion and invasion of udder pathogens. In a recent study, the specificity and efficiency of adhesion of 11 different $E$. coli strains was studied. The cell tropism of the tested E. coli strains was strongly strain-dependent and very variable from very low to high efficiency [133]. Binding can also occur to molecules of the cell matrix and Ditcham et al. [58] emphasised the need for an epithelial model that reflects as closely as possible the in vivo situation i.e. intact and unstimulated epithelium with no expression of extracellular matrix.

Fibronectin, a glycoprotein of high molecular weight, is produced by mammalian cells in tissue culture [170]. Faris et al. [72] tested the ability of $70 \mathrm{E}$. coli strains, isolated from bovine mastitis in Australia, Denmark, Norway and the USA, to bind fibronectin in vitro. Fifty-three strains $(76 \%)$ interacted with iodinated fibronectin at a level exceeding $5 \%$ of the total radioactivity added. In a recent study of Lammers et al. [133] 11 E. coli mastitis strains bound fribonectin to approximately the same extent as a fibronectin binding Staphylococcus strain with impaired fibronectin-binding protein expression (20\% of the wild type). None of the tested E. coli strains was able to bind fibronectin efficiently. It is known that in the normal mammary gland fibronectin is not present at the apical side of the epithelium. In the gland it is a normal 
component of the basement membrane of the epithelium where it is present as an insoluble matrix. It is also present at the surface of myo-epithelial cells and fibroblasts. LPS increases cell surface-associated fibronectin in fibroblasts in vitro [127]. Frost et al. [78] showed that two hours after I.M. infection with E. coli, epithelial lesions occurred in the teat sinus. The basement membrane was exposed [26] but lesions never went beyond the basal membrane.

It is clear that $E$. coli is primary an extracellular pathogen that is involved in I.M. infection [97]. Most studies dealing with the capability of E. coli, isolated from clinical mastitis, to adhere to mammary epithelia, do not indicate any important role for adherence. The organisms generally do not invade mammary tissue but remain in the lumen of the teat canal and lactiferous sinus. According to our current knowledge it is clear that the pathogenicity of coliforms isolated from acute mastitis cases is not related to invasion and/or colonisation. The role of these virulence factors is less clear in cases of chronic coliform mastitis [66]. Binding of E. coli to fibronectin in vivo, remains questionable. The greater residual number of bacteria in the gland after milking when compared to the previous milking, indicates that infection has progressed and the faster the bacteria multiplicate, the higher their numbers will be, but colonisation is not necessarily involved [23]. In the field, it is generally accepted that frequent milkout of $E$. coli infected cows is helpful for the treatment of coliform mastitis. In a recent study, the effect of frequent milkout was tested on the outcome of experimentally induced E. coli mastitis in cows. However, under these conditions, frequent milkout did not appear to be an efficacious treatment for moderate to severe E. coli mastitis [137], indicating that the bacteria replicate very fast.

During clinical coliform mastitis it can not be excluded that temporary reversible attachment of the E. coli pathogen occurs on the intact epithelium of the lactiferous sinus. This can not be defined as adhesion because this association is not followed by any specific receptor-mediated binding and colonisation as seen in the gut with enteropathogenic E. coli strains. Most studies show that adherence of $E$. coli pathogens to the epithelium does not exist or is at very least weak. However, such a reversible binding could eventually trigger secondary mediator release of cytokines that attract inflammatory cells. MAC-T cells (a nondifferenciated bovine mammary epithelial cell line, [107]) secrete IL-1 in response to endotoxin stimulation and $\mathrm{IL}-1$ is an important mediator for the release of the bovine IL- 8 by MAC-T cells [20]. NO release from mammary epithelial cell lines was also measured in response to endotoxin [21].

\subsection{Endotoxin as local mediator}

Virulence of coliforms and the induction of an inflammatory reaction depend on their ability to replicate in the organism and to destroy cellular structures. During multiplication, destruction and lysis, they release an outer-membrane component, the endotoxin or LPS [68], a thermostable molecule that is a unique structural component of the cell wall of the Gram-negative pathogens. Two phenotypic forms of coliforms with slightly different LPS can be distinguished: smooth with complete LPS sidechains and rough with incomplete LPS side-chains [65, 154, 169]. Many studies have shown that the pathogenicity of $E$. coli in the mammary gland is associated with LPS. LPS is considered to be a key molecule in the pathogenesis of this disease [41]. This is based on the following facts: (1) LPS is released as a result of the lysis and growth of $E$. coli in the lactiferous sinus [68]. Once the bacteria reach the teat cistern they will grow very fast, $8-10$ fold increase every two hours, releasing a lot of LPS. (2) I.M. administration of LPS induces the same local signs as observed 
during E. coli mastitis [53, 176]. (3) Pretreatment with polymyxin B (an LPS neutralising agent) or its simultaneous administration reduces and delays the febrile and leukopenic responses to I.M. LPS, and prevents the reduction in plasma zinc [262].

LPS is responsible for many pathophysiological signs observed during Gram-negative bacterial infections in ruminants such as fever, changes in the number of circulating leukocytes (leukopenia, leukocytosis), complement activation, activation of macrophages, increase of venular permeability, changes in plasma levels of metabolites, minerals, acute phase reactants and hormones, etc. LPS induces a defence response, especially in low doses. Intravenous administration of high doses of LPS may produce lethal shock [143, 144].

Although the pathogenic potential of purified bacterial LPS is well documented in general, the role of LPS in the pathogenesis of coliform mastitis has not been completely resolved. At the one hand there is no doubt that locally released LPS may play an important role in many of the local inflammatory signs during coliform mastitis [31]. However, it seems that its influence is short lasting and that it does not necessary cover all inflammatory changes. For example, the pre-treatment with polymyxin B only marginally influenced the degree of udder inflammation and it had no effect on the increase in SCC [262]. Twenty years ago Brooker et al. [26] already showed that two toxines were involved in experimentally induced E. coli mastitis: (1) the endotoxin, and (2) a heat labile cytotoxic compound that appears in a filtrate of $E$. coli culture. At that time Brooker et al. [26] already mentioned that the generally accepted concept that I.M. infusion of LPS produces a reaction indistinguishable from $E$. coli is not justified.

\subsection{Endotoxin as systemic mediator}

I.M. infusion of polymyxin B at 30 or $60 \mathrm{~min}$ after LPS only prevented the increase in plasma lactate dehydrogenase (E.C.1.1.2.3) activity and moderated the decrease in plasma zinc concentration. This treatment failed to alter the clinicopathologic course of endotoxin-induced acute mastitis [262]. The possible absorption of LPS from the inflamed udder during coliform mastitis into the general circulation, and its significance at systemic level is not so clear and has been discussed in literature during the last decades (see e.g. [144]). LPS was detected in the plasma of 3 out of 12 cows during the first $10 \mathrm{~h}$ after I.M. E. coli challenge. Thereafter, only low LPS concentrations were detected in blood plasma. LPS concentrations of 55, 134 and $93 \mathrm{pg} / \mathrm{mL}$ were reached for a very short lasting period [64]. This short lasting event might be due to a fast clearance of LPS in plasma or to a limited release of LPS from the mammary gland into the circulation. The values corresponded with those obtained from naturally occurring gangrenous E. coli mastitis [89], in which $85 \pm$ $68 \mathrm{pg}$ LPS $/ \mathrm{mL}$ was detected in blood plasma. The sporadic detection of limited LPS amounts in plasma contrasts with the massive LPS amounts that are released in the mammary gland during E. coli mastitis [246]. In the LPS model, the inflammatory reaction is induced by "bolus injection"; in the $E$. coli infection model, LPS is released during several hours $[64,93,97,124,161$, 167, 210, 244, 245]. Most LPS mastitis models described in literature are performed after peak lactation. In these "bolus" LPS mastitis studies, LPS seems to be effectively detoxified, and low levels of cytokines, produced during the inflammatory process, are the primary cause of the moderate systemic effects. The defence mechanism of the animal is not compromised at that moment. Milk production loss is less pronounced during LPS mastitis than during E. coli mastitis. Milk production losses in the uninflamed quarters are negligible in LPS mastitis, but substantial during $E$. coli mastitis (more pronounced systemic effects). Reticulorumen motility is only inhibited during E. coli mastitis 
and changes in plasma haptoglobin are more pronounced during E. coli mastitis, although they occurred sooner during LPS mastitis [143, 144].

In a recent study, LPS mastitis was induced in high yielding Holstein cows, 512 weeks after parturition, by I.M. infusion of $500 \mu \mathrm{g}$ into one quarter. The first milk sample was taken $4 \mathrm{~h}$ after I.M. LPS challenge and contained elevated LPS levels. These LPS levels gradually decreased over the entire course of the experimental period [258]. The data of I.M. increase of LPS are in agreement with those obtained by $\mathrm{Ziv}$ et al. [261] and Hartman et al. [92], who also found an increase of LPS in blood plasma. However, in the study of Yagi et al. [258] no LPS could be detected in serum obtained from the milk vein or the jugular vein, which is more compatible with current concepts. The discrepancies between the results obtained in the study of Ziv et al. [261] in the '70s and the recent study of Yagi et al. [258] are not inexplicable. Under field conditions, coliforms have been isolated in blood samples from diseased animals [253]. To our best knowledge, this has not been confirmed in experimentally induced coliform mastitis [190, 208] but this finding certainly needs more attention in the future. Especially the interplay between mediators from bacterial origin, such as endotoxins and non-LPS toxins, and the release of endogenous mediators (e.g. TNF- $\alpha$ ) during coliform septicaemia in the cow should be focused.

\subsection{Endotoxin clearance}

In the study of Dosogne et al. [64] E. coli counts were about $2 \times 10^{5}$ colony forming units $(\mathrm{cfu}) / \mathrm{mL}$ milk. The LPS release from E. coli during a $6 \mathrm{~h}$ growth period was $16.8 \mu \mathrm{g}$ (inoculum size of $10^{5} \mathrm{cfu} / \mathrm{mL}$, [235]). The calculated amount of LPS in milk from infected quarters was approximately $10^{5}$ times higher than the highest LPS value observed in blood. This suggests that a very large proportion of LPS is detoxified locally inside the inflamed mam- mary gland during $E$. coli mastitis, probably by neutrophils. A significant detoxification system is acyloxyacyl hydrolase (AOAH), which is present in bovine neutrophil granules [154]. AOAH hydrolyses two acyl chains of the lipid A core of the endotoxin, resulting in a decreased toxicity whereas the immunogenic properties of LPS are largely maintained [169]. In some cows, a decreased blood neutrophil AOAH activity was observed immediately after calving [60]. The fact that LPS was only detected in the plasma of animals with the highest cfu counts in milk suggests that LPS absorption is probably to a high extent dependent on the number of bacteria within the mammary gland and can therefore also be prevented by bacterial growth inhibition [64]. In the case LPS is absorbed from the udder into the systemic circulation (outside the portal hepatic system), it will reach the lung circulation first and activate the pulmonary alveolar macrophages. In this way the effective inactivation capacity by the von Kupffer cells of the liver is evaded. The same phenomenon occurs when the ability of the liver to eliminate LPS fails due to liver disease [36]. The general phrase that animals suffering from coliform mastitis show signs of endotoxinemia should be avoided. In fact they rather show signs of toxinemia caused by TNF- $\alpha$. Endotoxinemia is probably more the exception than the rule. Many animals however, may rather suffer from a mediator shock. The highest amounts of blood plasma TNF- $\alpha$ are found in severely diseased cows $[98,102]$. There are various indications that LPS might not be released from the mammary gland into the general circulation during LPS mastitis (discussed in [102, 143, 144]).

\section{HOW NEUTROPHILS SEQUESTER AND KILL E. COLI}

The first line defence mechanism against $E$. coli invading the mammary gland is based on the resident phagocytes, mainly 
mononuclear cells. Most chemotactic factors are produced by the host but also some bacterial factors act as chemoattractant (e.g. the LPS of E. coli). However, unlike human neutrophils, bovine neutrophils lack the formyl-methionyl-leucyl-phenylalanine (fMLP) receptor [228]. After a complicated cascade of release of biological substances and activation of the endothelium, neutrophils migrate into the mammary gland and finally also appear in the fluid of the lactiferous sinus [31]. Several antimicrobial systems exist in the mammary gland [31, 119, 178]. However, it is the massive influx of neutrophils that will resolve the infection through sequestration and killing of the invading bacteria $[31,180]$.

Immunological recognition is mainly accomplished by specific antibodies $\left(\mathrm{IgG}_{2}\right.$ and $\operatorname{IgM}$ ) which recognise the bacterium through Fab-regions and bind to PMN via Fc-receptors on the PMN plasma membrane [177]. There is a synergy between the $\mathrm{Fc}$ and $\mathrm{C} 3 \mathrm{~b}$ receptors activity and PMN reactive oxygen species (ROS) production [171]. Targowski and Niemialtowski [229] observed an increased $\mathrm{Fc}$ receptor expression and phagocytosis after in vitro migration of bovine PMN through membranes. This was confirmed in further studies by Berning et al. [12] and Worku et al. [257]. During migration of PMN into milk in response to $E$. coli, increased binding of C3b was observed [54]. Following adherence of $E$. coli to surface receptors on the PMN, phagocytosis and respiratory burst are triggered. The process of opsonisation, though not essential for phagocytosis, certainly promotes the uptake of $E$. coli by PMN, which is energy-dependent and requires the presence of a functional cytoskeleton [103]. The cytoskeleton machinery, sequentially activated following receptor stimulation, is thought to envelope the micro-organism in a "zipper mechanism" [86]. Thus, PMN are fully armed to confront invading E. coli. Generally, there are two different microbicidal mechanisms within the PMNs: the oxidative and the non-oxidative system.

\subsection{Oxidative mechanism of $E$. coli killing}

Within seconds after the recognition of E. coli, PMN become activated and generate powerful reactive oxygen species, such as superoxide anions $\left(\mathrm{O}_{2}^{-}\right)$, hydrogen peroxide $\left(\mathrm{H}_{2} \mathrm{O}_{2}\right)$, halogen reactive species and hydroxyl radicals $\left({ }^{\circ} \mathrm{OH}\right)$ by partial reduction of $\mathrm{O}_{2}$ [138]. This process is linked to the respiratory burst and associated with the PMN's cell membrane and granules (e.g. [8, 13, 196, 221]). Many different mechanisms of oxidation-reduction reactions are involved in intracellular bacterial destruction [194, 252]. The oxygendependent mechanism is the most prominent mechanism for $E$. coli destruction [222, 228]. Baldridge and Gerard [9] reported that an increase in $\mathrm{O}_{2}$ consumption by PMN takes place when phagocytosis is triggered. This coincides with the increase of the hexose monophosphate shunt activity and glucose consumption. The respiratory burst is based on the activation of a membrane-bound oxidase (NADPH-oxidase), which catalyses the following reaction $[7,198,199]$ :

$$
2 \mathrm{O}_{2}+\mathrm{NADPH} \rightarrow 2 \mathrm{O}_{2}^{-}+\mathrm{NADP}^{+}+\mathrm{H}^{+} .
$$

The oxygen molecule is central in this phenomenon $[3,7,8]$. Its importance was highlighted by inefficient PMN bactericidal activity under anaerobic conditions [150]. For each molecule of $\mathrm{O}_{2}$ consumed $4 \mathrm{O}_{2}{ }^{-}$ ions are generated, resulting in an intravacuolar $\mathrm{O}_{2}^{-}$release of about $4 \mathrm{~mol} / \mathrm{L}$ [194].

Another $\mathrm{O}_{2}$-dependent microbicidal system uses halides and the enzyme myeloperoxidase (MPO, E.C. 1.11.1.7). MPO and/or eosinophil peroxidase catalyses the reaction between $\mathrm{H}_{2} \mathrm{O}_{2}$ and $\mathrm{Cl}^{-}$, $\mathrm{I}^{-}$, or $\mathrm{Br}^{-}$, with formation of the highly toxic hypohalides and the subsequent oxidation of amines [7, 198, 199]. MPO is localised in the azurophilic granules of the PMN and 
reaches the micro-organisms when the granule content is released into the phagolysosome [44], providing a destructive environment for phagocytosed $E$. coli. Among these ROS are also a variety of oxidised halogens, including hypohalite ions [4, $196,233]$ and a variety of chloramines [232].

Root and Cohen [196] have suggested several possible direct sites of action for ROS, related to their microbicidal activity. These include: (1) unsaturated carbon bounds that may lead to toxic lipid peroxidation; (2) sulphydryl groups leading to the destruction of sulphydryl containing enzymes; (3) amino group and possible peptide bound breakage; and (4) nucleic acids. In vitro studies with $\mathrm{O}_{2}^{-}$generating systems such as xanthine oxidase [197] suggest that $\mathrm{O}_{2}{ }^{-}$are far more toxic for E. coli if they operate in the MPO- $\mathrm{H}_{2} \mathrm{O}_{2}$ halide system. This leads to the production of powerful halogenated oxidising agents such as $\mathrm{ClO}^{-}$ions, which have a bactericidal effect by halogenating the bacterial proteins. The halogenated oxidising agents are produced inside the phagosome when PMN ingest bacteria [44]. It is also generally agreed that ROS boost oxygen-independent microbicidal activity [194].

Nitrogen oxide also acts as an antimicrobial agent in the presence of ROS [130]. It synergises bactericidal activity of $\mathrm{H}_{2} \mathrm{O}_{2}$ against $E$. coli by damaging the $E$. coli DNA and declining bacterial glutathione contents [182]. In human, NO release is a part of the integrated response of PMN stimulated by phorbol-myristate-acetate (PMA, an ester that activates the NADPH-oxidase in the cell membrane). NO together with $\mathrm{O}_{2}{ }^{-}$produces other oxidants, such as peroxinitrite (ONOO-; [40]).

\subsection{Non-oxidative mechanisms of $E$. coli killing}

Non-oxidative mechanisms of bacterial killing by bovine PMN are less well defined, but they heavily rely on the ability of PMN's enzymes and proteins to alter the membrane permeability of E. coli [191, 207]. Studies have demonstrated that a cationic bactericidal/permeability-increasing protein (BPI) present in both rabbit and human PMN is the basic non-oxidising bactericidal agent of these PMN toward several strains of E. coli bacteria [70, 251]. Bovine lactoferrin has also considerable inhibitory effect on E. coli growth [15]. Moreover, extracellular matrix proteins such as laminin promote neutrophil motility and attachment to $E$. coli, enhance phagocytosis activity of neutrophils, substantially prime neutrophil ROS production and stimulate lysozyme release into the phagosome [188, 230]. Lysozyme has the capacity to neutralise and strongly interact with E. coli LPS [173]. Laminin also enhances the neutrophil bactericidal activity against E. coli, the effect being larger with increasing IL- $1 \beta$ and IL-8 concentrations. Also fibronectine enhances the bactericidal activity, synergised by TNF- $\alpha$ [213]. The cytosindependent cell-mediated bactericidal activity of PMN is also crucial for killing of E. coli, especially during the early phase of E. coli mastitis.

Another non-oxidative antimicrobial agent is PMN elastase. Elastase degrades the outer membrane protein A of E. coli, which is located on the surface of the bacteria $[11,250]$. Mice lacking PMN elastase and other granule-proteases are more sensitive to E. coli infection [10] and other bacterial and fungal infections [194]. Activation of proteases provokes the influx of a large amount of ROS into the phagolysosome, resulting in a strong anionic charge. This leads to the release of cationic granule proteins, facilitating the bactericidal process. The anionic charge is compensated by a $\mathrm{K}^{+}$flux from cytosol into the phagosome [194]. The large amount of $\mathrm{K}^{+}$ in the phagosome is a crucial factor for the non-oxidative bactericidal activity by its effect on proteases and $\mathrm{pH}$ homeostasis $[111,153,194]$. 


\section{Extracellular ROS Intracellular ROS}
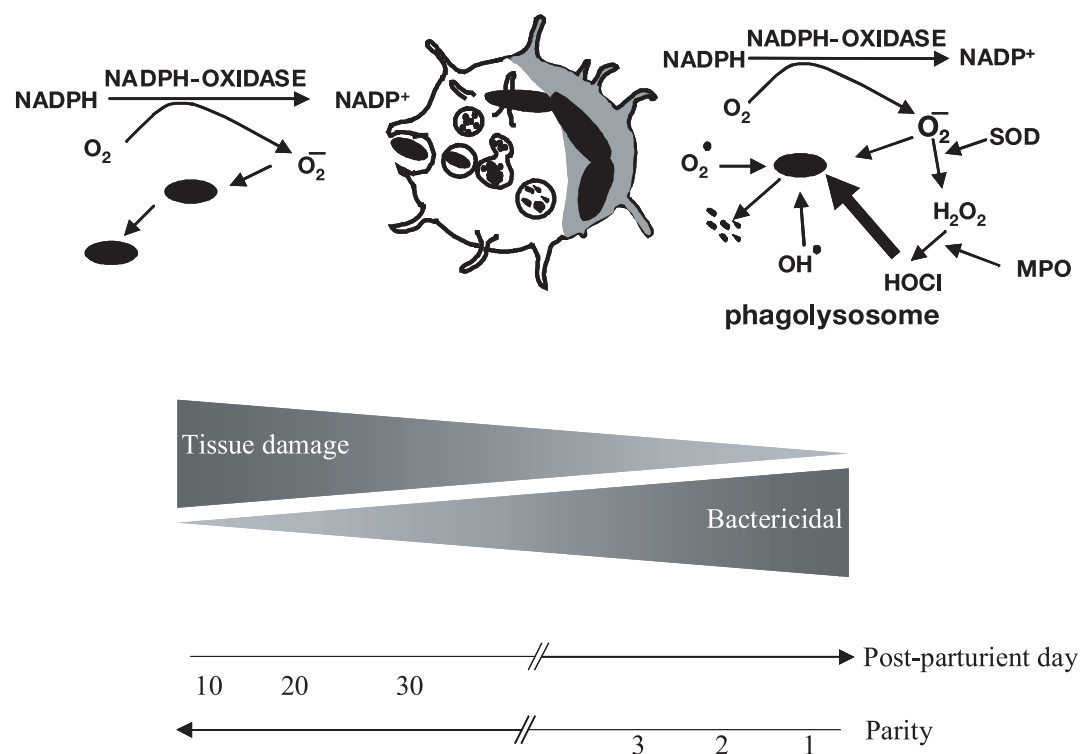

Figure 1. Diagram illustrating the hypothesis that during severe E. coli mastitis extracellular production of reactive oxygen species (ROS) by polymorphonuclear leukocytes may be impaired and contribute to the tissue damage. Normally, ROS for bactericidal activity is produced intracellularly for effective destruction of bacteria with a minimum of tissue damage. This hypothesis is based on the study of the kinetics of chemiluminescence: (1) there is a difference between extracellular and intracellular ROS production of both blood and milk PMN during different stages of lactation, and (2) in blood and milk, extracellular ROS production by PMN is more pronounced in older cows. This may lead to an impaired bactericidal capacity of resident milk PMN and boost tissue damage in older cows $[158,161]$.

The osmotic forces in the vacuole must be considerably high to enable the shrinkage of ingested bacteria (about $50 \%$ of their original volume). Osmotic forces also activate PMN granule proteases [194]. High extracellular osmolarity decreases the killing capacity of PMN against E. coli [90]. Many other factors such as calcium ions [139], granulocyte colony-stimulating factor (G-CSF) [134], growth hormone and insulin-like growth factor (IGF)-I [108] enhance PMN killing capacity against E. coli.
In short, successful intracellular killing of $E$. coli depends on ROS production. Bovine blood and milk PMN ROS production can be measured by chemiluminescence (CL; see [157-159]), which is associated with the bactericidal capacity of PMN [3, $84,187,249]$. Studies on CL kinetics in PMN revealed extra- and intracellular events during ROS production [25, 49, 69, 73]. Figure 1 provides a scheme of a hypothesis showing extra- and intracellular ROS production of PMN in relation to possible tissue damage or effective killing 
depending on some physiological parameters (age and lactation stage). This hypothesis is based on findings from studies performed on healthy and experimentally infected cows [158, 161]. A low ROS production of resident milk PMN is observed during early lactation. This is more pronounced in older cows where most of ROS is produced extracellularly. This may compromise milk PMN bactericidal capacity and boost tissue damage. Our preliminary findings indicate that during $E$. coli mastitis both extracellular and intracellular ROS substantially increase from 6 to $48 \mathrm{~h}$ postinfection. The studies may suggest that in moderate responders, ROS is mainly produced intracellularily whereas in severe responders it is extracellular ROS.

The above explanation is a general basic knowledge about killing of $E$. coli and is not the whole explanation about PMNE. coli interactions during and after phagocytosis. There are interspecies differences as well as inter-subspecies differences on oxidative and non-oxidative PMN bactericidal mechanisms [225, 228].

\section{THE LPS, TLR 4, TNF- $\alpha$ AND NO CONNECTION}

Peptidoglycan monomers and LPS are unique to all Gram-negative cell walls. They are elements of the pathogen associated molecular patterns (PAMP) and bind to pattern-recognition receptors (PRR) that are present on a variety of defence cells of the body causing them to synthesise and release a variety of cytokines. The LPS interacts with LPS-binding protein and CD14, which in turn promotes the ability of the Toll-like receptor, TLR4 (a PRR) on macrophages to respond to the LPS with the release of various pro-inflammatory cytokines. These inflammatory mediators bind on target cells via specific receptors and initiate inflammation. Toll-like receptor proteins, homologues of the Drosophila protein Toll, have been detected on the sur- face of mammalian cells [14]. They are important in the responses of macrophages to bacterial, viral, and fungal antigens. TLR2 and TLR4 have candidate genes for resistance to several diseases as they recognise broad classes of PAMPs, such as peptidoglycans and LPS [254]. Very little TLR4 is present on the surface of human neutrophils. TLR2 is important for response to Gram-positive bacteria, bacterial peptides and zymosan and is more abundant on the neutrophil. TLR4 activates the inflammatory gene expression through nuclear factor $\kappa \mathrm{B}(\mathrm{NF \kappa B})$ [156]. Granulocyte-macrophage colony-stimulating factor (GMCSF) and granulocyte colony-stimulating factor (G-CSF) dramatically up-regulate TLR2 and CD14 expression [129]. Recent in vitro studies have shown that mammary epithelial cells may participate in the immunoregulation during mastitis via cytokine production. A MAC-T cell line was utilised to investigate the expression of interleukin1 mRNA and its subsequent secretion after E. coli LPS stimulation and it showed that these cells secrete IL-1 in response to LPS. IL-1 also appeared to be an important mediator for the release of the IL-8 [20, 107].

During coliform and LPS mastitis in ruminants, IL-1, IL-6 and IL-8 [210], platelet-activating factor [184], prostaglandins [5, 27, 186], activated complement C5 (C5a; [211]) and NO [16, 19], are released locally. In milk, an increase in TNF- $\alpha$, a cytokine of particular interest in the pathogenesis of $E$. coli mastitis, is observed [98, 102, 211, 219]. The increase in TNF- $\alpha$ occurs faster during LPS mastitis than during $E$. coli mastitis but it peaks higher during I.M. E. coli infection. TNF- $\alpha$ remains unchanged in non-challenged quarters $[16,102]$. Absorption of this cytokine into the systemic circulation is highest during E. coli mastitis. Plasma levels are much lower than in the milk and correspond with maximal pyrexia [102]. Several studies show that the amount of TNF- $\alpha$ released in 
milk correlates with the severity of the disease [16, 98, 102, 210, 219].

Many of the biological activities of LPS are mediated by TNF- $\alpha$. LPS and cytokines stimulate the synthesis of NO, which is a vasodilator. NO is a diatomic free radical. It is lipid soluble and diffuses easily through cell membrane. It is short lived and usually degrades or reacts within a few seconds. The natural form is a gas that reacts with a variety of molecules and mediates a large spectrum of biological effects. NO is synthesised from L-arginine. An inducible NO synthase (E.C. 1.14.13.39, iNOS) is expressed by a variety of cells, especially monocytes, as a result of triggering with substances of microbial origin such as LPS and TNF- $\alpha$. Bovine monocytes produce NO in response to LPS $[1,114,223]$. NO is produced by macrophages in response to invading pathogens and acts as an antimicrobial agent. It is also cytotoxic and can induce apoptosis if produced in excessive amounts $[6,166]$.

Several studies on ruminants have shown a relationship between LPS, TNF- $\alpha$ and production of NO. The increase in TNF- $\alpha$ is followed by a delayed increase in $\mathrm{NO}_{\mathrm{x}}\left(\mathrm{NO}_{2}+\mathrm{NO}_{3}\right)[16,19]$. The $\mathrm{NO}_{\mathrm{x}}$ production lasts longer in E. coli challenged quarters. A causal relationship between TNF- $\alpha$ and $\mathrm{NO}_{\mathrm{x}}$ production was observed in studies in which E. coli LPS was injected intravenously [115]. It seems that severe cases of coliform mastitis are accompanied by the highest increase in blood plasma concentrations of both TNF- $\alpha$ and $\mathrm{NO}_{\mathrm{x}}[16$, 98]. The increase in $\mathrm{NO}_{\mathrm{x}}$ and TNF- $\alpha$ during E. coli mastitis can't be inhibited by antibiotic treatment [16] indicating that its release is LPS mediated. Initially called endothelium derived factor (EDRF), NO causes vasodilation. It is released after the fever peak, that is, at the moment of the delayed phase of vasodilation occurring during LPS induced mastitis in lactating goats and cows [53]. It is not impossible that NO is involved in this delayed phase of hyperemia.

\section{SEVERITY CLASSIFICATION OF COLIFORM MASTITIS}

\subsection{Clinical severity classification}

Mastitis is a multifactorial disease and its risk factors can be classified into three groups of disease determinants: the pathogen, the environment and the host [234]. To combat mastitis, sophisticated models, such as the five-point-plan, have been adopted worldwide and have resulted in significant reduction of subclinical mastitis. However, despite classical efforts for control and prevention, the susceptibility of cows to coliform infection is increasing [131, 205, 224]. Moreover, from both epidemiological and experimental studies it can be concluded that severity of coliform mastitis is of much more concern than its incidence. Many high producing cows are extremely sensitive for $E$. coli infections around parturition and during early lactation. Clinical mastitis with grave systemic symptoms occurs at parturition and during early lactation, whereas during mid and late lactation signs are mild to moderate [97]. Estimation of the sensitivity of a cow for I.M. E. coli infection refers to its clinical expression. In the field, these signs are ranked from mild, to moderate and severe, and resistant animals are insensitive. Severe clinical mastitis is characterised by sudden onset with grave systemic signs: diarrhoea, inhibition of rumen motility, paralysis, hypothermia, very high pulse rate and hypersalivation. It is well recognised that the severity of coliform mastitis determines the outcome of the disease as well as the degree of production loss. Therefore, accurate evaluation of the severity in the field is needed to determine appropriate treatment and management measures. However, there is no simple on-farm evaluation system to characterise disease severity that relates accurately to the outcome of the disease. For example, bacteraemia was never observed in field cases by Powers et al. [189] whereas Cebra et al. [42] reported bacteraemia in $1 / 3$ of the cows that were 
suffering from severe clinical mastitis. Wenz et al. [253] isolated bacteria from the blood of some cows that were scored as "mild reaction".

\subsection{Scoring severity under field conditions}

Despite appreciable efforts to introduce clear definitions and scoring for mild, moderate and severe based on systemic signs [253], there is still some confusion in the field. In the field, oversimplifying the term mastitis may lead to wrong interpretation of the terms mild, moderate and severe. The terms mild and moderate are sometimes (mis)used to describe the local symptoms; e.g. mild is often used to describe appearance of clots or flakes in the milk with little or no signs of swelling of the mammary gland. In the field this is usually associated with infections by minor pathogens [128] such as coagulase negative Staphylococci (CNS) and Corynebacterium bovis. Moderate and severe are often used to refer to visibly abnormal milk accompanied by swelling in the affected mammary quarter. Generally, a correlation exists between the local clinical signs and the severity of systemic symptoms. However, discrepancies have been noticed, especially during the onset of severe $E$. coli mastitis around parturition where slow progressing and less visible local swelling is clinically misleading because this mild local reaction will be rapidly succeeded by severe symptoms of shock [93, 95, 245]. The dilemma for farmers and veterinarians is that the lack of inflammation and clinical symptoms in the udder often makes rapid diagnosis difficult. By the time a diagnosis can be made, it is too late to save the animal. On the other hand, during mid and late lactation the local symptoms of the disease may be so short lived and mild, that it is difficult for a milker to recognise this self-curing condition [97]. It is clear that under field conditions there is a need for exact ranking of severity through application of clear and generally accepted definitions. Mis- classification through misuse or use of less specific definitions may lead to dubious conclusions. Agreement on definitions would also be in favour of comparing field and experimental studies. The terms mild, moderate and severe that are used by Wenz et al. [253] under field conditions are only based on systemic parameters such as rectal temperature, hydration status, rumen contractility and attitude of the animal. The principle to relate severity to systemic factors is in agreement with the severity classification used under experimental conditions (e.g. [31, 59, 93, 98, 124-126, 210, 242, 245]).

\subsection{Experimental severity classification}

Studies of Hill et al. [95] with E. coli mastitis demonstrated that those animals which displayed a pronounced local acute inflammatory reaction showed fewer systemic symptoms than those that did not. Occasionally, and only during early lactation, bacterial multiplication in the mammary gland induces only a very slow acute phase response. The progress made by the invading pathogen is so fast, or the acute inflammatory reaction by the host so slow, that the cows show very grave systemic signs because of the lack in local control of the pathogen. This clinical type of mastitis was defined by Schalm et al. [203] as a peracute mastitis and corresponds with the severe responders in the study of Vandeputte-Van Messom et al. [245]. Over the years, several attempts have been made to estimate severity under experimental conditions. It was suggested by Heyneman et al. [93] to distinguish between moderate and severe responders during early lactation. Although this method has been shown to be useful at many occasions, one of the problems is that in some cases the severity response is very gradual, especially if the whole lactation period is considered. In this case severity classification as proposed by Hirvonen et al. [98] into mild, moderate and severe responders is 
preferred. Parameters that can be used to estimate severity under experimental conditions can be divided into local and systemic disease parameters.

\subsection{Local disease parameters}

Fast and uncontrolled growth of I.M. E. coli with large numbers of bacteria in the udder cistern can occur. This is especially related with the period of parturition and early lactation $[26,41,59,79,93,97,125$, $126,145,167,210,241,244,245]$ and this explosive growth of I.M. E. coli is less apparent during established lactation [16, 97, 98, 102, 195, 210]. Also older cows exhibit higher cfu during coliform mastitis [190, 241]. In these studies the number of bacteria that grow in the gland cistern (estimated as cfu) is linked to the severity of coliform mastitis. Cows in the severe group have significantly more bacteria in the gland cistern than cows in the moderate groups. Under experimental conditions this can be quantified by measuring the area under the curve (AUC) of bacterial growth. AUC has been successfully used in many experimental studies [59, 125, 126, 145, 241, 242]. LPS may increase dramatically at sites of bacterial replication especially during fast and uncontrolled growth of E. coli in the udder cistern. Although methods have been developed to measure the LPS content of milk [92, 258, 261] no attempt has been made to estimate severity on basis of the endotoxin dosage in the udder cistern. A good severity indicator may be TNF- $\alpha$ in milk, because of its typical release during acute $E$. coli mastitis and not during S. aureus mastitis [195]. Generally, most studies indicate that the amount of TNF- $\alpha$ that is released in milk is closely associated with peracute signs of coliform mastitis [98, 210, 211, 219] but practically no difference in local TNF- $\alpha$ response was found between $E$. coli and LPS mastitis [16, 102]. Exact quantification of the expression of mRNA for TNF- $\alpha$ in cells derived from infected mammary glands through reverse transcription polymerase chain reaction might be helpful in the future.

During a balanced I.M. inflammatory reaction, bacterial growth will be under control and only a few bacterial cfu will develop in the udder cistern of the cow. Low levels of LPS will be released leading to moderate and specific cytokine pattern production by the macrophages which will promote optimal body innate defence mechanisms and minimal systemic signs such as fever and leukopenia. Animals reacting in this way were called moderate responders [245]. They typically show a steep increase in SCC, due to fast migrating neutrophils that inhibit bacterial growth effectively. There is experimental evidence that these neutrophils might also destroy the endotoxin in the mammary gland [60]. Slow neutrophil influx is observed in severe responders (see Fig. 2, [245]) and they might start releasing their proteases and ROS in the mammary tissue before reaching the pathogens. For some reason, neutrophils are stacked in the tissue. However, this phenomenon could not be confirmed by Shuster et al. [210]. As E. coli population can double every $20 \mathrm{~min}$, a delay of just $20 \mathrm{~min}$ in neutrophil arrival in lacteal secretions has a significant effect. A 1-h delay in neutrophil recruitment into the mammary gland could result in an 8-fold larger number of $E$. coli to kill and that much more endotoxin to detoxify [119].

In a recent study, in vitro growth of E. coli in milk was studied to explore the hypothesis that milk from individual cows differs in its growth medium properties for E. coli, and whether possible variation could be related to specific milk constituents. The growth differed substantially between individual cows within an incubation period comparable with the early phase of I.M. infection, suggesting that the growth medium properties of milk could be of importance in the pathogenesis of $E$. coli mastitis and subsequent outcome of disease [123]. 

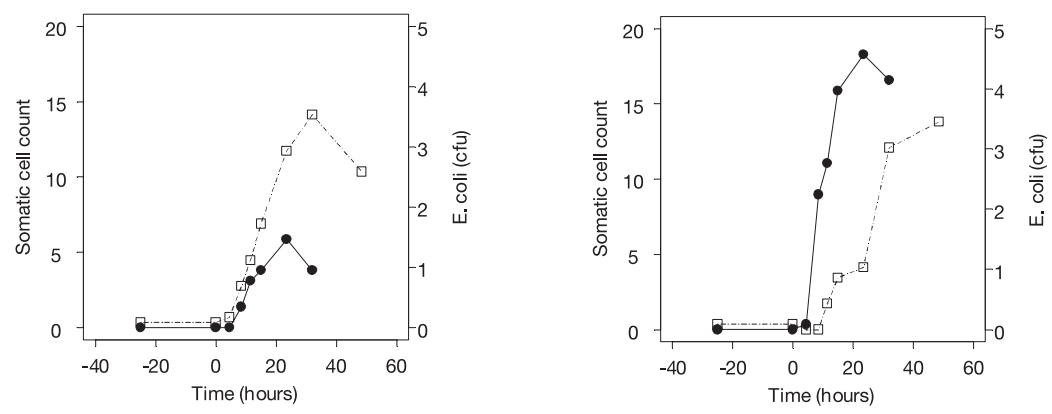

Figure 2. Multiplication rate of E. coli $\left(\times 10^{6} / \mathrm{mL} ; \bullet\right)$ in inoculated mammary glands and pattern of leukocyte influx $\left(\times 10^{5} / \mathrm{mL} ; \square\right)$ into milk in (a) periparturient moderate responders compared with (b) those in severe responders during experimentally induced E. coli mastitis. (Figure taken from the original paper [245], with permission.)

\subsection{Systemic disease parameters}

During experimental studies, differences in the fever response were observed that were related to severity $[102,210$, 245]. Under field conditions, rectal temperature is one of the disease parameters used to classify severity [253]. Careful interpretation of local TNF- $\alpha$ release is needed because it is known that at low doses, TNF- $\alpha$ has a protective role during invasive infections so that increase in TNF- $\alpha$ may be a normal response to bacterial invasion. For example, although practically no difference in local TNF- $\alpha$ response was found between the E. coli and LPS mastitis model, the increase in plasma TNF- $\alpha$ peaked highest after I.M. E. coli infection [16, 102]. TNF- $\alpha$ might have been absorbed from the E. coli infected udder and/or secreted from activated mononuclear cells such as monocytes and macrophages in the body [102]. The subsequent grave systemic signs may be due to abnormal regulation of a normal TNF- $\alpha$-mediated response. The decreased rumen motility that has been observed during coliform mastitis under both experimental $[102,143,245]$ and field conditions [253] may be related to the increase of TNF- $\alpha$ in the blood plasma. The pivotal role of TNF- $\alpha$ in this host reaction is suggested by four lines of evidence: (1) the decrease in rumen motility is not observed or at least very mild during experimentally induced endotoxin mastitis [102, 143]; (2) TNF- $\alpha$ is one of the earliest mediators secreted by the host in response to I.M. E. coli infection [195]; (3) TNF- $\alpha$ in blood plasma is higher after I.M. E. coli infection than during endotoxin mastitis [102] and (4) administration of TNF- $\alpha$ to goats elicits inhibition of rumen contractions [240]. One of the criteria used by Wenz et al. [253] under field conditions is rumen contractility. Clinical mastitis induces a nonspecific acute phase response (APR) and the initiation of APR is also thought to be caused by the production of TNF- $\alpha$ [102]. Changes in plasma haptoglobin occurred sooner in endotoxin mastitis than during E. coli mastitis. However, the total response was practically similar in both models [102]. These observations are in accordance with the findings in the study of Hirvonen et al. [98] where serum haptoglobin did not correlate with the severity of the disease. Serum amyloid-A (SAA, another acute phase protein) rose gradually in the severely affected cows, and significant differences were found between severely vs. moderately or mildly affected cows at day 4 . Serum TNF- $\alpha$ concentrations only increased in the severely affected cows. During severe clinical coliform mastitis a decrease in total milk yield occurs. It 
is not surprising that milk production was also reduced in uninfected quarters during coliform mastitis $[59,93,99,100,102$, $152,167,210,245]$. The magnitude of this reduction is the result of: (1) a local effect induced by the invading pathogen and in which inhibition of milk synthesis and tissue damage is involved, and (2) the degree of systemic disease; e.g. decrease in gastro-intestinal motility and subsequent reduction in availability of milk precursors [30, 93, 143, 144]. The loss in milk production in the uninfected contralateral quarters on day 2 after infection, has been used as a criterion to classify cows as moderate or severe responders to experimental E. coli mastitis after parturition [93, 245]. Milk production losses in uninflamed quarters are negligible in endotoxin mastitis but substantial during E. coli mastitis, probably due to pronounced systemic effects [102]. Harmful effects are first seen systemically, due to excessive release of cytokines. The animals are depressed, have ruminal stasis and diarrhoea, cardiovascular collapse resulting in shock and multiple system organ failures which in its most extreme form may lead to death [97]. The infected gland shows extensive tissue destruction [97] and decrease in milk secretion [152]. In the uninfected glands milk production is depressed for several days [93, 245].

\subsection{Is severity predictable?}

Severity classification and prediction under experimental conditions have received a lot of attention over the past 15 years, especially in connection with treatment regimens where sham treated animals are compared with specific drug treated animals (e.g. [244]). Nowadays we know that several host determinants influence the sensitivity for coliform mastitis, i.e. stage of lactation, number and function of peripheral PMN, SCC, age of the host, genetic resistance, nutritional status, other periparturient diseases, and the vaccination status [180]. The variability in severity to $E$. coli
Table I. Correlations between the phorbol myristate acetate (PMA) and zymosan induced respiratory burst of bovine neutrophils expressed as $\mathrm{O}_{2}^{-}$generation/cell (nmoles $\mathrm{O}_{2}^{-} /$cell) and $\mathrm{O}_{2}^{-}$ $\mathrm{O}_{2}^{-}$generation capacity (nmol $\mathrm{O}_{2}^{-} \times$neutrophil number) prior to the inoculation of Escherichia coli and the severity of mastitis ${ }^{1}$. (Table taken from the original paper [93], with permission.)

\begin{tabular}{|c|c|c|}
\hline \multirow[t]{2}{*}{$\begin{array}{l}\text { Characteristic } \\
\text { of blood neutrophil }\end{array}$} & \multicolumn{2}{|c|}{$\begin{array}{c}\text { Decrease } \\
\text { in production of }\end{array}$} \\
\hline & Milk & $\alpha$-Lactalbumin \\
\hline Neutrophil number & $-0.58 *$ & $-0.48^{*}$ \\
\hline $\begin{array}{l}\text { PMA - induced } \\
\mathrm{O}_{2}^{-} \text {generation / cell }\end{array}$ & -0.16 & -0.22 \\
\hline $\begin{array}{l}\mathrm{H}_{2} \mathrm{O}_{2} \text { generation / cell } \\
\text { Zymosan - induced }\end{array}$ & -0.18 & -0.26 \\
\hline $\begin{array}{l}\mathrm{O}_{2}^{-} \text {generation / cell } \\
\text { PMA - induced }\end{array}$ & $-0.80 * *$ & $-0.67^{*}$ \\
\hline $\begin{array}{l}\mathrm{O}_{2}^{-} \text {generation capacity } \\
\text { Zymosan - induced }\end{array}$ & $-0.77 *$ & $-0.72 * *$ \\
\hline $\mathrm{O}_{2}^{-}$generation capacity & $-0.90 * * *$ & $-0.75 * *$ \\
\hline
\end{tabular}

${ }^{1}$ Severity of mastitis was estimated as the percentage decrease in milk and $\alpha$-lactalbumin production on day +1 and +2 after inoculation of $E$. coli into the udder.

${ }^{2}$ Correlation coefficients with probabilities $* P \leq$ $0.05, * * P \leq 0.005, * * * P \leq 0.001$ for 14 cows.

mastitis during early lactation can be so large that extremely high numbers of animals per group have to be included in the study. Several prediction markers have been tested in relation to severity of $E$. coli mastitis under experimental conditions, among them: total number of circulatory leukocytes and PMN (see Tab. I; [93]), the oxidative burst of PMN (see Tab. I), PMN chemotaxis and neutrophil alkaline phosphatase (NAP, E.C. 3.1.3.1). The number of circulating peripheral leukocytes just before bacterial inoculation also predicted the severity estimated by the AUC of bacterial counts and residual milk production (reviewed by [33]). Variation in severity could not be explained by pre-infection 
NAP levels. Of the pre-infection tests for leukocyte function, chemotaxis of PMN isolated from the peripheral blood at day -2 and -1 , and immediately prior to infection best predicted the outcome of the induced E. coli mastitis [125]. Predictions were most significant within $24 \mathrm{~h}$ before challenge (see Tab. I). Predictive significance was rapidly lost when samples were taken earlier (from day -2 to -6 , [125]). It was concluded that PMN functions could not be used to predict severity over longer periods, probably due to the short half-life of these cells. On the other hand, very short significant predictions can be made (within two days) which may be useful for some experimental purposes.

\subsection{Modulation of severity}

Activation of innate immune responses by LPS can be inhibited by various soluble molecules that bind LPS and neutralise its activity. However, LPS is not a classic virulence factor but it contributes to the pathogenic potential of Gram-negative bacteria by activation of host defensive systems which ultimately results in both, clinical signs and tissue damage. The pro-inflammatory nature of LPS plays a critical role in the successful elimination of the infecting pathogen [75]. Furthermore, in many LPS-models the effect on several biological systems seems to be dependent on the dose [151]. Therefore, modulation rather than complete inhibition of the action of the LPS molecule is preferable.

Modulation of inflammation and tissue damage in coliform mastitis can be obtained through antibodies directed against the cell wall [65] or through LPS scavengers such as polymyxin B [262]. Nowadays, the tools, techniques and products to study and modulate host-pathogen interactions are made available by advances in molecular biology. The cloning and expression of proteins such as recombinant bovine soluble (rbos) CD14, may provide ways of minimising damaging effects of LPS during acute coliform mastitis. CD14 binds and neutralises
LPS and causes local recruitment of neutrophil after binding of CD14-LPS complexes to mammary epithelial cells [180].

\section{LIFESPAN OF PMN: FROM MATURATION TO SENESCENCE}

\subsection{Proliferation, differentiation and maturation of PMN}

During postnatal life hematopoiesis is restricted to the bone marrow, whereas the liver and the spleen are inactive but retain their hematopoietic potential. All blood and immune cells originate from a selfrenewing small population of pluripotent stem cells (CFU-S) that can replicate themselves, or can become committed to a particular development pathway. PMN are formed through the multi-step process of granulopoiesis, from the colony-forming unit of granulocytes (CFU-G) through myeloblasts, promyelocytes, myelocytes, metamyelocytes, and band cells. Precursor cells undergo striking morphologic, biochemical and functional changes during granulocytic maturation. These changes are associated with significant changes in cell size and nuclear shape, and with the development of stage-specific proteins essential for phagocytosis and bacterial killing. Glasser and Fiederlein [83] provided knowledge about the acquisition sequence of functional properties during human granulopoiesis. Data were frequently extrapolated to the bovine species, although species variation in neutrophil function has been clearly demonstrated [225]. Because alterations in the granulopoiesis may underlie the significant changes in the function, number and maturity of circulating PMN observed during coliform mastitis, attention was drawn to the niche of these cells in the bovine. A prerequisite for studies on the maturity of cells is a reliable separation method, in order to obtain enriched cell fractions of different maturation stages. Recently, Van Merris et al. [238] developed 


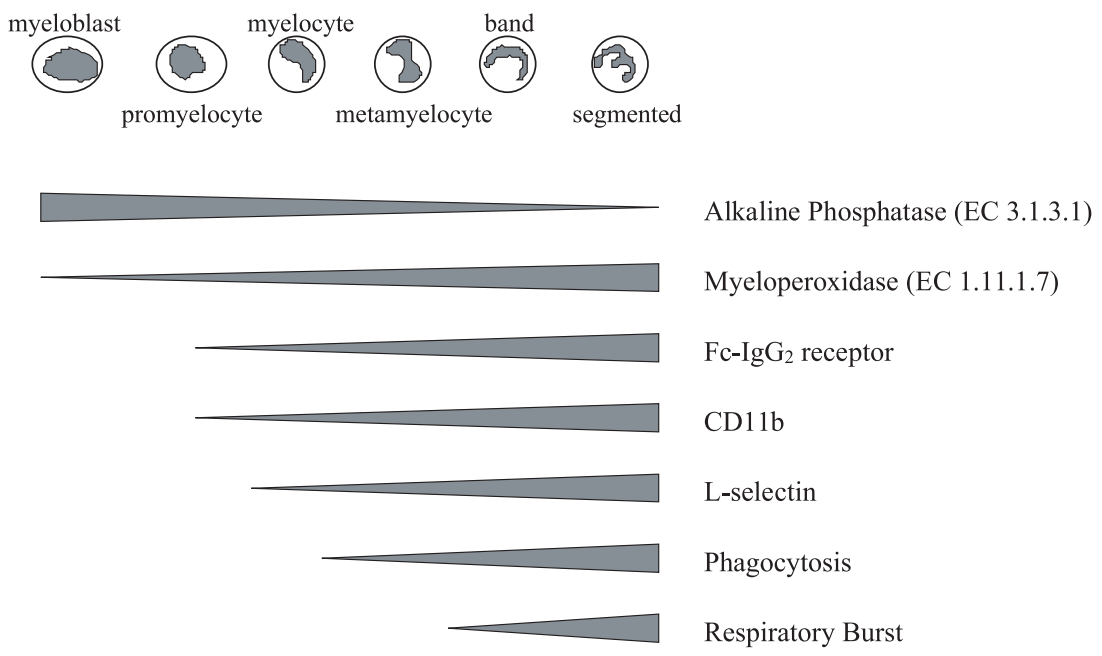

Figure 3. Stepwise acquisition of functional properties in bovine bone marrow cells during granulopoiesis. (Figure adapted from the original paper [239], with permission.)

a discontinuous Percoll gradient on which centrifugation of bone marrow resulted in three maturation-dependent cellular fractions. In a subsequent study, the functional maturation sequence during bovine granulopoiesis was established and proposed to be the following: myeloperoxidase activity - Fc-IgG2 receptor expression - CD11b expression - L-selectin - phagocytosis respiratory burst activity (Fig. 3) [239]. In analogy to human hematopoiesis [83], the acquisition of various biochemical and functional properties in bovine PMN was found to take place in different stages of maturation in the bone marrow. The efficiency of PMN against invasion of the mammary gland was previously shown to be highly dependent on the rate of diapedesis into the infection site [95] and on the ability of these PMN to generate ROS [93]. Although the immature cells expressed already the membrane adhesion molecule CD11b, they were not capable to rapidly migrate to the infected mammary gland, and ingest and kill efficiently the invading bacteria. The limited chemotactic and phagocytic ability in immature cells could be due to membrane rigidity with poor cel- lular deformability, in association with a large nucleus [141]. The incapacity to produce ROS was attributed to the absence of membrane-bound NADPH-oxidase activity, as myeloperoxidase was already present in the rare azurophilic granules at the promyelocytic stage [239]. These findings were in general agreement with previous observations of Silva et al. [212]. Thus, when maturation is impaired due to an increased proliferation rate, a higher number of immature cells will appear in the circulation. These findings support the hypothesis postulated by Guidry and Paape [88], namely that the presence of myelocytes, metamyelocytes and band cells (left-shift) observed during acute coliform mastitis in early lactation may compromise the cows' resistance by supplying more cells that are morphologically immature and functionally inadequate.

Alkaline phosphatase is present in substantial amounts in the cytoplasm of PMN [248]. In human, NAP activity fluctuates in a variety of physiological (pregnancy, stress) and pathological conditions (mononucleosis, myeloproliferative disorders) (summarised in [174]). Conflicting data 
resulted in an unclear and still controversial relationship between cell maturity and NAP activity. Some authors observed the NAP activity mostly in functionally and chronologically older neutrophils $[17,118]$; others assessed highest NAP in immature cells $[120,256]$. The latter indicated that elevation of NAP activity of circulating PMN may coincide with the increased release of precursor cells from the bone marrow. A significant increase in NAP activity was observed during experimental E. coli mastitis [94]. Van Werven et al. [242] demonstrated that the increase was a result of increased enzyme activity per neutrophil, rather than an increase of the number of neutrophils exhibiting NAP activity. The NAP-inducing factor was shown to be identical to G-CSF [200], the growth factor thus being responsible for starting the synthesis of the enzyme in the neutrophil. Therefore, the enhanced NAP activity after onset of mastitis was believed to be induced by G-CSF, reflecting an increased proliferation and differentiation of bone marrow granulocytes [94].

It has been postulated that cells leave the bone marrow more-or-less by a pipeline mechanism, the older cells being released first [149]. The mechanisms that control the release of mature PMN from the bone marrow into the circulating pool are poorly understood. Anatomical localisation of the hematopoietic cells close to vascular spaces, and the development of transient holes in the venous sinuses to allow egress of marrow cells have been suggested as mechanism. Also the developmental changes in the nucleus and the cytoplasm of the maturing cells that increase their motility, deformability, and chemotactic ability could attribute to the release of terminally differentiated PMN from the hematopoietic compartment into the efferent vascular space [140]. Van Eeden et al. [236] assigned a possible role to L-selectin in the release of PMN from the bone marrow in human, as L-selectin was highly expressed on mature PMN in the postmitotic pool in the bone marrow [231].
With active bone marrow release there was an increase in the number of PMN expressing high levels of L-selectin in the circulation [236]. However, levels of L-selectin on circulating PMN never reached levels expressed in the bone marrow, suggesting that L-selectin is shed as PMN enter the circulation. Recently, Monfardini et al. [168] provided evidence for a maturationdependent increase in L-selectin expression during granulopoiesis in the bovine. The findings were consistent with previous reports in human that a high number of circulating bovine PMN expresses CD62L but at a lower level than mature bone marrow granulocytes. PMN can shed L-selectin from their surface as a part of a de-adhesive event during recruitment into a site of inflammation [46]. The loss of L-selectin when crossing the endothelial barrier in the bone marrow upon release into the blood stream could be a similar process. Alternatively, high levels of L-selectin on mature PMN might keep them attached to the endothelium of the bone marrow sinusoids, and stimuli for release may activate the proteolytic cleavage of L-selectin [236].

\subsection{Regulation of the granulopoiesis}

The process of granulopoiesis is strictly controlled by regulatory growth factors, comprising cytokines and colony-stimulating factors (CSF), to ensure the maintenance of a steady state. The hematopoietic growth factors have pleiotropic effects on proliferation, differentiation and functional activation of precursor cells [164]. They interact at various levels of the differentiation cascade, from unipotent stem cell to mature PMN. The biologic effects of the growth factors are mediated through specific receptors on the surfaces of target progenitor cells.

Hoeben et al. [101] investigated the effect of hormones and metabolites, of which the concentration changes substantially around parturition in the bovine. Using an optimised cell culture assay for the bovine [237], it was demonstrated that 
$\beta$-hydroxybutyric acid (BHBA) and acetoacetic acid (AcAc) induced significant inhibitory effects on the proliferation of hematopoietic cells at concentrations observed after parturition. In a study of Van Werven et al. [243] a high pre-infection BHBA concentration was strongly negatively correlated with the pre-infection number of circulating PMN. Bovine pregnancy-associated glycoprotein (bPAG) also reduced the proliferative activity of bovine progenitor cells. Hydrocortisone-21-acetate (HCAc) inhibited the hematopoietic activity of bovine bone marrow at concentrations of 10 to $100 \mathrm{ng} / \mathrm{mL}$ [101]. At calving, a short lasting cortisol peak of approximately $20 \mathrm{ng} / \mathrm{mL}$ is observed, whereas during mastitis increases up to $100 \mathrm{ng} / \mathrm{mL}$ are possible [215]. The inhibitory effects of BHBA, AcAc, bPAG, and HCAc may be involved in the changes in the number, differentiation and maturity of circulating PMN after calving [101], as the circulating pool is largely depending on the proliferative capacity of the bone marrow.

The action of growth factors, inflammatory mediators, metabolites and hormones on the proliferation, differentiation, and function of PMN is provided in Figure 4.

\subsection{Ageing of PMN}

After having exerted their role in immune function PMN die by senescence [255]. Aged PMN undergo spontaneous apoptosis in the absence of pro-inflammatory agents prior to their removal by macrophages [201], thus preventing the release of their cytotoxic content. One of the dominant theories of senescence, the soma theory [122], suggested that replicative cells accumulate genetic damage, resulting in functional decline. Arguing against this proposal in the case of ageing of PMN, were the findings of Chatta et al. [45] and Born et al. [18] indicating that the proliferative and differentiation capacity of hematopoietic progenitor cells was largely unaffected by ageing in humans. However, the ability of progenitors to proliferate and differenti- ate in response to hematopoietic factors does not necessarily guarantee that the resulting PMN are competent [35]. Inflammation and infection do increase the rate of PMN production, shortening the maturation time and leading to the release of immature immune cells in the circulation. Schalm and Lasmanis [204] reported that during mastitis the myeloid/erythroid ratio in bovine bone marrow increased above 1.0, reflecting an intensified granulopoiesis, probably to ensure replenishment of the PMN reserve and the return to homeostasis.

\section{HOST FACTORS THAT INFLUENCE SEVERITY}

\subsection{Stage of lactation}

Defense of the bovine mammary gland is continually challenged by environmental exposure to bacteria, and many factors affect the outcome of this challenge. On average $1 \%$ of mammary quarters in the dairy cow population will have I.M. infection with Gram-negative bacteria compared to an infection rate of $35-50 \%$ for Gram-positive bacteria [68]. The rate of clinical mastitis during the first 2,4 , and 8 weeks after parturition increases from $25 \%$, to over $45 \%$ and to $60 \%$, respectively [109]. A high percentage of I.M. infections present at parturition also develop into clinical mastitis during the first 60 to 70 days of lactation [104]. The early postpartum period is a period of high risk for severe clinical mastitis because of extreme sensitivity for a number of animals for I.M. infection with ordinary environmental bacteria such as coliforms [93, 124, 125, 245]. Severe clinical mastitis with grave systemic symptoms typically occurs around parturition and during early lactation. Coliform mastitis after peak lactation is a moderate and self-curing disease. In some cases (during mid and late lactation) the symptoms of the disease are so mild and so short lasting, that it is difficult for a milker to recognise this self-curing condition 


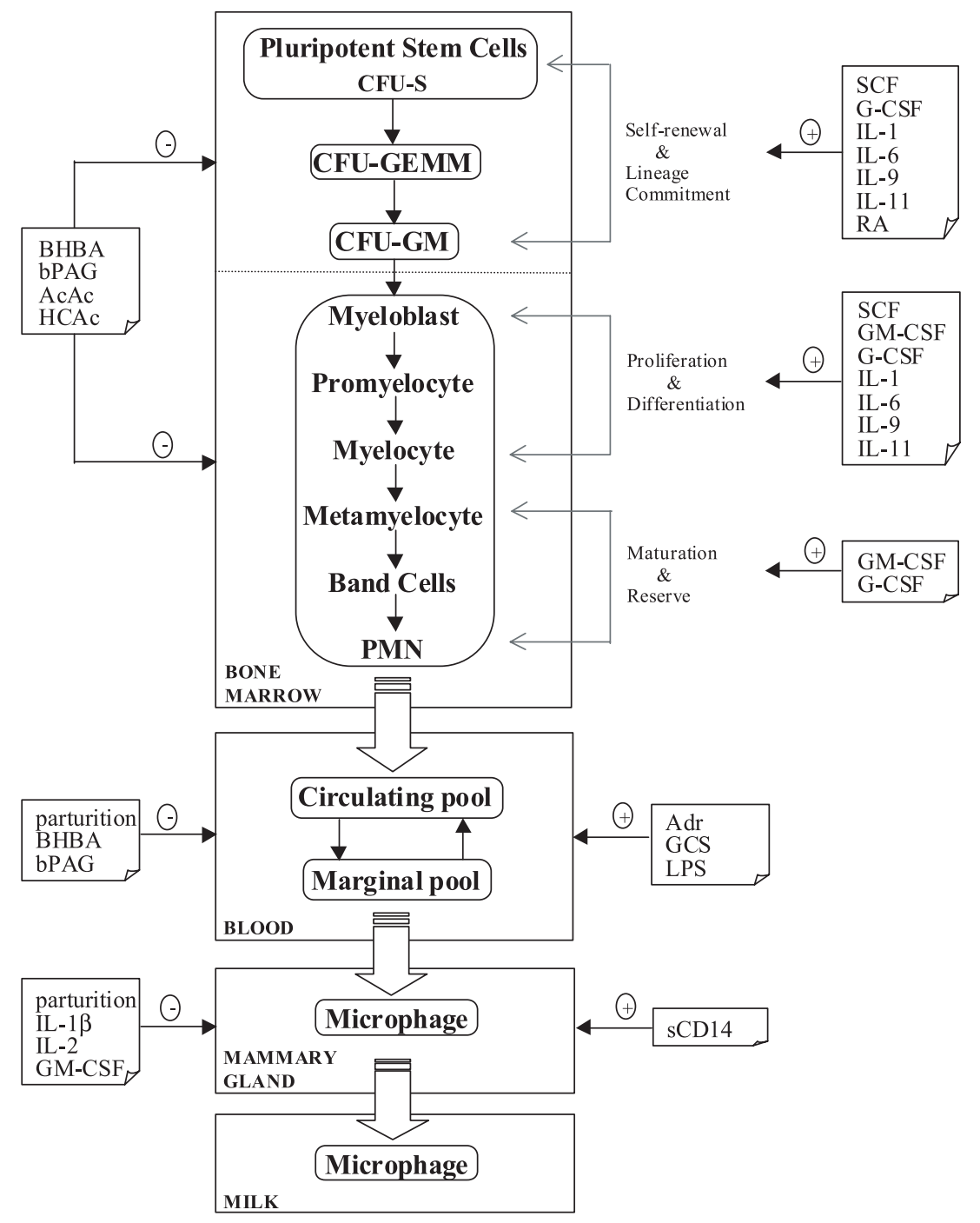

Figure 4. Action of growth factors, inflammatory mediators, metabolites and hormones on the proliferation, differentiation, and function of PMN in the bovine. CFU-S, colony-forming units spleen; CFU-GEMM, colony-forming units of granulocyte, erythrocyte, monocyte and megakaryocyte; CFU-GM, colony-forming units granulocyte and monocyte; SCF, stem cell factor; GM-CSF, granulocyte-macrophage colony-stimulating factor; G-CSF, granulocyte colony-stimulating factor; BHBA, $\beta$-hydroxybutyric acid; AcAc, acetoacetic acid; bPAG, bovine pregnancy-associated glycoprotein; IL, interleukin; RA, retinoic acid; Adr, adrenaline; GCS, glucocorticosteroid.

[97]. Today, we know that severity of bovine $E$. coli mastitis is mainly determined by cow factors rather than by the pathogenicity of the invading pathogen. For example, it is well recognised that the bovine immune system is less capable of battling pathogens during the periparturient period and early lactation. Although exact causes for a compromised immune system are not fully understood, they are 
believed to be at least influenced by hormonal and metabolic changes associated with pregnancy, parturition, and onset of lactation $[57,61,62,87,126,147,148$, $162,185,226]$.

\subsection{Number and function of circulating PMN}

The PMN population represents a major line of defence against infection in the bovine mammary gland. Indeed, the speed of PMN influx into the udder tissue can determine the severity of the mastitis [96, 245]. However, during the periparturient period the number and the different functions of circulating PMN, such as diapedesis, phagocytosis, and bacterial killing are altered [31,57]. Major variations in PMN number and function occur within a fairly small period of about one week after parturition (Fig. 5). Interestingly, studies performed during early lactation (up to two months after parturition), indicate that the number of circulating PMN correlates with the severity of Gram-negative mastitis [93, 126, 243, 245]. Different characteristics of peripheral PMN, such as stimulated CL activity, cytochrome c reduction, chemotaxis, and stimulated L-selectin and CD11b expression, have also been related to the severity. In addition, other pre-infection metabolic parameters in blood, such as $\beta$-hydroxybutyric acid, non-sterified fatty acids, glucose, $\mathrm{Mg}^{2+}, \mathrm{Ca}^{2+}$, cortisol, and cholesterol concentration, as well as in milk, such as SCC, albumin, fat, and casein production, have also been found to be associated with the severity of $E$. coliinduced mastitis $[52,59,93,116,121,126$, 210, 245, 259]. Other studies have compared the functionality of PMN between early and later stages of lactation [158160]. The basal adhesion molecule levels of CD62L and CD18 at the surface of circulating PMN and the phagocytic activity of blood and milk PMN have been described to be similar during early lactation as compared to later stages of lactation [63, 210]. Interestingly, ROS production and killing activity of blood and milk PMN were significantly decreased in early lactation [63, $158,159,161]$. Because PMN functions are markedly altered around parturition (Fig. 5), detailed studies have been done during the last years in our laboratory. CL of stimulated blood and milk PMN was lower during early lactation as compared to mid or late lactation. Moreover, the ratio of stimulated milk to blood PMN CL was lower immediately after calving [158]. The low responsiveness of milk PMN towards PMA during early lactation could have resulted from a weaker stimulation of protein kinase $\mathrm{C}$ and NADPH-oxidase [117]. In addition, differences were observed in the kinetics of the PMN CL curve. Luminol-enhanced blood PMN CL kinetics showed a biphasic course during mid and late lactation. However, within the first ten days after parturition, only the immediate first peak was observed. CL in milk PMN was always monophasic with minimal intensity and durability during early lactation [158]. The luminol-dependent $\mathrm{CL}$ system requires $\mathrm{H}_{2} \mathrm{O}_{2}[73,142]$ and both intra- and extracellular events contribute to this CL [69]. It is likely that the intracellular $\mathrm{H}_{2} \mathrm{O}_{2}$ production and $\mathrm{MPO}-\mathrm{H}_{2} \mathrm{O}_{2}$-halide activity is higher in blood than in milk PMN and their impairment is maximal during early lactation (Fig. 6; [158]). The decrease in ROS production in early lactating cows seems to be related with the diminished viability of milk-resident PMN detected in this period.

\subsection{SCC and age of the host}

There is evidence to suggest that minor pathogens increase milk cell counts and can help to protect the udder against mastitis [128]. In addition, herds with low SCC have a higher incidence of environmental mastitis compared to herds with high SCC [85, 205, 227, 247]. However, the correlation between SCC in the milk and the immune response of the udder to infection is not clear. Indeed, mastitis incidence and SCC levels are both higher in older cows. This paradoxical finding could be well 

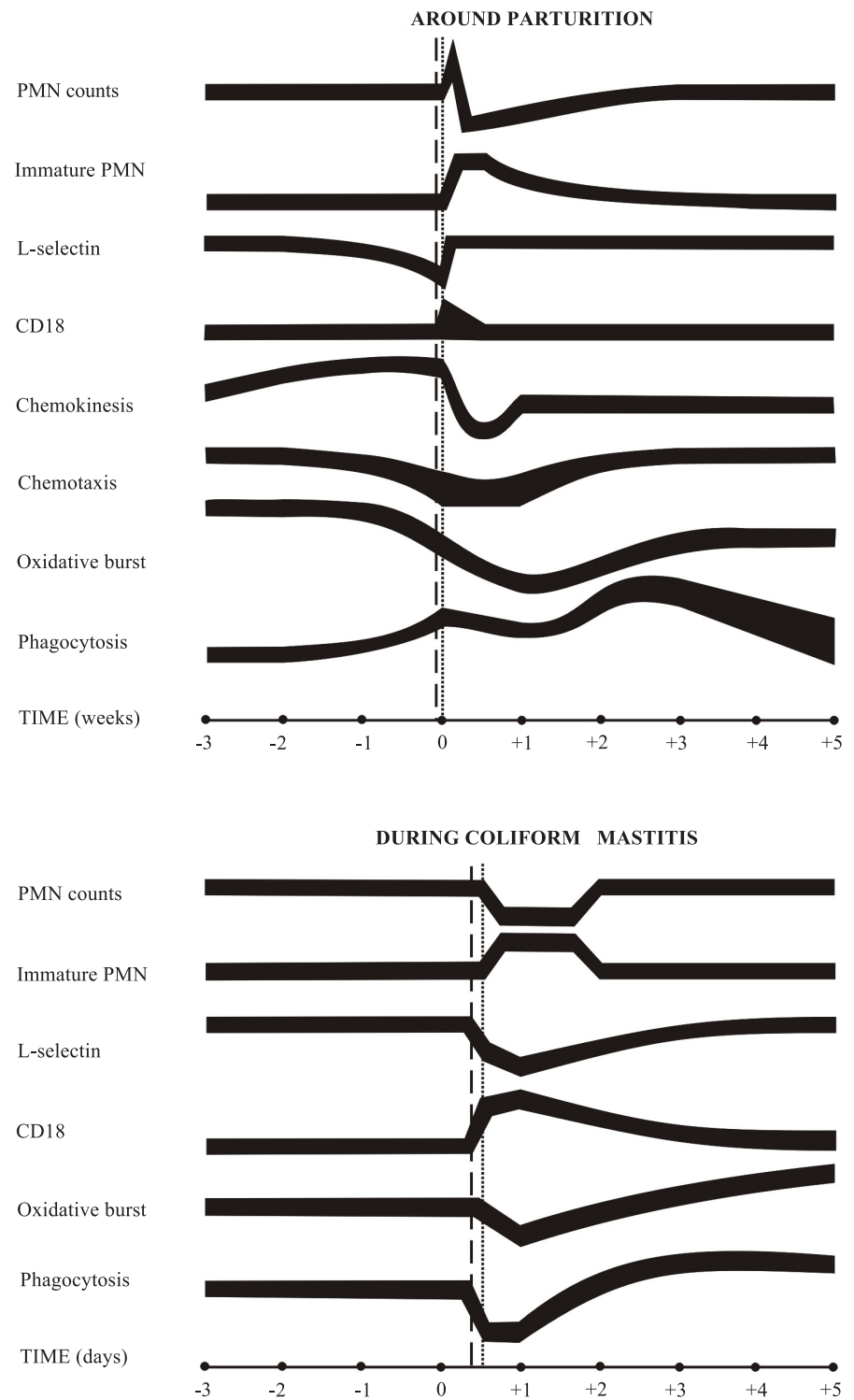

Figure 5. Schematic illustration showing major dynamic changes in circulating PMN numbers and functions around parturition and during coliform mastitis. The thickness of the curves reflects the degree of observed experimental variability with respect to a given parameter. The increase of catecholamines (dashed lines) and glucocorticoids (dotted lines) levels in blood occurs concomitantly with calving or shortly after coliform mastitis. (Figure taken from the original paper [57], with permission.) 


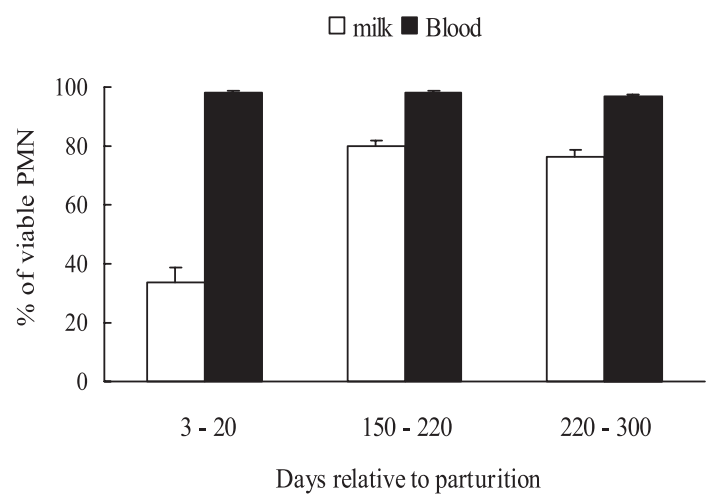

Figure 6. Viability of milk and blood PMN during early, mid and late lactation in dairy cows. Values are means \pm SEM of 10 cows. (Figure taken from the original paper [158], with permission.) related to the functionality of the resident milk cells. Indeed, milk PMN in primiparous cows have been found to have a higher viability and ROS production as compared to older animals [161]. Therefore, primiparous and older high-yielding cows should be evaluated in different categories.

\subsection{Nutritional and metabolic status}

The peripartum period represents a period of significant decrease in energy, protein, and trace element concentrations in blood that may influence the outcome of the disease. Vitamin $\mathrm{E}$ and $\mathrm{Se}$ are essential nutrients that share common biological activities. Deficiencies in either of these micronutrients have been related in increased incidence and severity of mastitis. They are integral components of the antioxidant defence of tissues and cells $[105,214]$. Elevated plasma concentration of ketone bodies in blood, due to the enormous increase in demand for energy by the onset on lactation at calving, has also a negative effect on PMN function and is associated with susceptibility to mastitis [226].

\subsection{Genetic resistance}

Several significant genetic associations have been found between the severity of the mastitis and several parameters, such as the number and different functions of circulating PMN in early lactation, the serum concentration of Ig, and the SCC. For details we refer to specialised reviews [51, 180].

\section{INFLAMMATORY PARAMETERS AND SEVERITY}

\subsection{Local signs}

Udder abnormalities (increased firmness, swelling, watery milk with clots or flakes) are often a first indication of mastitis. However, these udder and milk changes do not predict the overall severity of the disease. The severity of $E$. coli mastitis has been directly related to the level of bacterial counts in milk [59, 98, 145, 210, 245] and the loss of milk production, especially in the non-infected quarters [59, 93, 245].

\subsection{Circulating leukocytes}

PMN in blood and milk are important components of the mammary gland defence against coliforms [31]. Number and function of bovine PMN respond differently to E. coli experimental infection depending on the severity of the mastitis. It is likely that the more severe disease course of E. coli mastitis during early lactation is due to a delay in mobilisation rate of PMN into the udder [96, 210, 245] and a reduced capacity of PMN to generate ROS [93], 
resulting in failure to eliminate the bacteria from the infected quarters. The efficient migration of circulating PMN to the mammary gland depends on the correct expression and activation of several adhesion molecules. Bovine leukocyte adhesion molecules such as L-selectin (CD62L) and $\beta_{2}$-integrins play a key role in the initial contact and in the subsequent strong adhesion to the vessel endothelium, respectively $[56,218]$. Interestingly, in high-yielding cows infected with $E$. coli during early lactation, a higher increase of CD11b expression and a more pronounced decrease of CD11a and CD62L levels have been reported in severely diseased animals [55, 59]. These molecules are known to be indicators for the activation status of the cells. Therefore, the difference in expression level is probably related to the presence of bacteria in milk for a longer period in severely affected cows, which in turn release LPS and thereby extend the period of the activation status of blood PMN. During the first stages of experimental mastitis, the chemotactic response of leukocytes decreased in both, moderately and severely infected animals. The recovery of the chemotactic response of the leukocytes occurred more rapidly in moderately than in severely diseased cows [124]. It has been observed that early after challenge phagocytosis decreases in circulating PMN, but the initial decrease occurred faster in severely affected cows. From day 6 on after challenge, values increased over preinfection levels and remained higher in severely affected animals [59]. Heyneman et al. [93] found a correlation between ROS production during the inflammatory response and the severity of mastitis.

In moderately affected cows, the initial neutropenia was followed by a return to basal levels after 2 to 3 days. However, one week after infection severely diseased animals developed a neutrophilia during which metamyelocytes and myelocytes appeared frequently in the blood, and even became the predominant leukocyte types [94]. Possibly, the larger proportion of immature PMN partially accounts for the lower chemotactic response of the circulating PMN during experimental mastitis in the severely diseased cows $[125,245]$.

Neutrophil alkaline phosphatase activity was significantly higher in severe cases of mastitis during the 2nd week after inoculation. Basal NAP activity was regained after about two weeks in moderately diseased animals but lasted for several weeks in severely affected cows [94, 242]. The severity of the infection has been correlated with lower plasma $\mathrm{Zn}$ and $\mathrm{Fe}$ concentrations during the acute phase [145]. In addition, in severe mastitis highly persistent levels of cortisol were measured as compared with mild or moderate situations [98].

It seems that circulating PMN of severely diseased animals are in a status of increased activation for a longer period of time than moderately affected cows. Indeed, it has been observed that the clinical condition of severe cases only starts to deteriorate after one or two days postinfection, which is much later that the onset of clinical mastitis [98]. This idea is in agreement with the concept that severity of coliform mastitis can be estimated on basis of the milk loss in the uninfected quarters, 48 hours after infection [59, 93, 125, 244, 245].

\section{3. $P M N$ viability}

A crucial aspect of mammary gland non specific defence status is milk PMN viability, which is influenced by (patho)physiological conditions of the gland [157, 158, 161, 187]. Apoptotic PMN are removed through phagocytosis by macrophages. Necrotic cells are not promptly cleared by phagocytes and their chromatin proteins may boost prolonged inflammation [202]. A low viability of resident milk PMN is observed during early lactation and this may compromise the total phagocytic and bacteriostatic capacity of the teat cistern. This could facilitate the growth of E. coli, especially during their lag phase. However, it is far more efficient to clear the 
bacteria from the teat cistern with newly attracted viable PMN that engulf and kill the bacteria effectively. The increased milk PMN viability during LPS and E. coli mastitis that has been observed recently [157, 160] can be considered as a physiological homeostatic mechanism that could prevent inappropriate and prolonged inflammation. Mammary tissue damage may also be more important if viability is not optimal during E. coli mastitis. It is conceivable that milk PMN viability contributes to the pathophysiology and the outcome of E. coli mastitis.

\section{TISSUE DAMAGE AND PRODUCTION LOSS DURING E. COLI MASTITIS}

\subsection{Pathologic findings during $E$. coli mastitis}

General pathology books describe necrosis of the mammary epithelium during severe, naturally occurring clinical coliform mastitis [113]. Epithelial lesions appear very rapidly in experimental models where $E$. coli is infused I.M. with variable doses $\left(200\right.$ to $\left.10^{9} \mathrm{cfu}\right)$. Frost et al. [77] showed that after I.M. infection (approximately $10^{9} \mathrm{cfu}$ ) E. coli multiplied very rapidly in the teat sinus, lactiferous sinus and large ducts. Within one hour, epithelial lesions were seen on these places, especially in the teat sinus. After two hours epithelial lesions were extensive and there was microscopical evidence of inflammation. However, lesions never went beyond the basal membrane. At four hours post-infection, inflammation was seen in the ducts and secretory tissue and there was massive infiltration of the lesions with PMN. Especially in moderate cases, there was a minimum of alveolar involvement. The same sequence of events was observed when smaller numbers of pathogens were infused I.M. [26]. In very severe cases of coliform mastitis there is a limited inflammatory reaction with an extensive involvement of the secretory tissue. A rapidly ascending infection, spreading via the ductular system, was observed [79]. In its most severe form, with totally uncontrolled bacterial multiplication and all lactiferous sinus epithelia lost, interstitial tissue became totally haemorrhagic and the animal died of toxaemia within a few hours of infection [97]. In the early stages of experimentally induced E. coli mastitis, when lesions develop in the epithelium of the teat and lactiferous sinuses, neutrophils are in the subepithelial tissue. They first appear as mounds over the lesions but finally move through these lesions into the lumen of the gland into the milk [97]. Experimentally induced E. coli mastitis also promotes apoptosis and cell proliferation. During the later stages of moderate E. coli mastitis, apoptosis has been observed in the mastitic tissue. Expression of $\mathrm{Bcl}-2$ associated $\mathrm{x}$ protein (Bax, a proapoptotic protein) and IL-1 $\beta$ converting enzyme increased in the tissue at $24 \mathrm{~h}$ and $72 \mathrm{~h}$ post-infection. At $24 \mathrm{~h}$ Bcl-2 expression decreased. Induction of matrix metalloproteinase-9, stromelysin-1 and urokinase-type plasminogen activator was also observed in the mastitic tissue. Next to this, cell proliferation was also increased in the inflamed mammary gland [146].

\subsection{Tissue damage and milk loss vs. high SCC}

I.M. infection is the primary reason for increased SCC for all types of mastitis. A negative correlation exists between SCC and milk yield [50,192], indicating that a great part of the mammary epithelium may be damaged by the invading bacteria and/ or the phagocytes that were sent out by the defence system of the host. Decreased or lost milk production is an important aspect of clinical mastitis. High-producing cows might never achieve the total lactational output that would have been expected. Permanent blunting of milk production may also occur for the remainder of that lactation. This effect is very damaging when 
mastitis occurs before the cow reaches its peak lactation. Phagocytes, and more especially neutrophils, are necessary to eliminate the invading bacteria. PMN migrate through mammary tissue as a result of infection of the udder. Once within the cisterns, ducts and alveolar lumen of the gland, phagocytosis by PMN and subsequent degranulation may account for the negative correlation between SCC and milk production. Chemical compounds, such as ROS released from neutrophils can cause mammary secretory cell damage and reduced milk yield. Substances secreted by the pathogen may also cause damage. Although degranulation of neutrophils ensures the potentiation of the inflammatory reaction, it is usually undesirable in the very sensitive mammary gland [97]. In order to minimise mammary tissue damage and milk production loss, elimination of invading bacteria should proceed fast, probably rather because of the side effects of the activated phagocytes and their ROS than because of a direct effect of bacterial LPS.

\subsection{Do trafficking neutrophils cause damage?}

The mechanism by which tissue damage occurs during coliform mastitis is not yet fully understood. Tissue damage caused by neutrophils may originate from two sites: intratissular or intraluminal. The damage may originate from the inside of the parenchyma (intratissular), i.e. starting at the basal side of the epithelium. Theoretically, neutrophils trafficking in mammary tissue towards the luminal side of the udder might cause cell and tissue injury, especially when it occurs massively, and mainly through the release of mediators helping them to traverse the different obstacles (basal membranes, matrix and cells). It is not clear whether transcellular epithelial migration, as described for postcapillary venular endothelial migration, occurs during coliform mastitis [74]. Transcellular endothelial neutrophil migration mainly occurs through all or non-diaphragmed fenestrated endothelia (to our best knowledge, in the goat mammary gland, no such fenestrations were found, [28]). Because fenestrations are absent in mammary epithelium this mechanism is not expected in the mammary gland. However, a comparable mechanism could occur. In the inflamed gland some (damaged) epithelial cells can be expelled by neutrophils into the luminal surface of the ducts and cisterns to create "a gap" [97] through which neutrophils could traverse massively into the lumen under influence of a chemotactic gradient that starts in the postcapillary venules and increases toward this gap and the site of the nidus of infection. The process of venular migration starts around two hours after infection and an additional two to four hours is needed to reach the epithelium of the teat sinus. In mammary parenchyma, where postcapillary venules are closer to the milk alveolus, shorter times could be reached [183].

If LPS is used to induce the inflammatory response in the mammary gland, no lesions develop, and the PMN move between the epithelial cells and the tight junctions to get into the lumen of the gland [97]. This is in agreement with the finding that the drop in milk production during LPS mastitis is short lasting and that it is completely self-curing within 2-3 days depending on the dose [53]. We have the experience that primary cultured bovine mammary epithelial monolayers have variable and underdeveloped intercellular junctions compared to the in vivo situation. However, neutrophil migration induced by C5a did not change electric resistance over the cell layer over a short period. Moreover, cell lysis or epithelial detachment were not observed [216-218]. The above mentioned findings are in agreement with the basic concept that paracellular migration of neutrophils is locally modulated and that release of proteolytic enzymes in the matrix (e.g. elastase) does not occur. Instead, elastase is only activated in the cytoplasm-membrane at the end of the pseudopodia $[43,106]$, probably to affect 
the cell junctions protein complex, cadherin/catenin. Boulanger et al. [22] demonstrated activation of gelatinase activity in isolated bovine neutrophils stimulated with LPS and PMA. Nevertheless, no epithelial cytotoxicity could be detected. This may explain why aprotinin, a serine proteinase inhibitor which inhibits the proteolytic activity, had no effect on epithelial damage in a culture of MAC-T cells. However, in other models, tissue lesions have been observed following neutrophil diapedesis. For example, neutrophil-mediated injury to gut epithelium leading to disruption of the epithelial barrier function with consequent organ dysfunction was studied in vitro, using a colonic epithelial cell line. In this model it was demonstrated that neutrophilderived proteases can mediate spatially delimited disruption of epithelial apical junctions during transmigration [82].

\subsection{Intraluminal induced damage}

Intraluminal induced damage originates from the luminal part of the gland, in cisterns and ducts where cells and chemical mediators of the host are released to eliminate the invading bacteria around the nidus of infection. As the inflammatory cascade progresses and spreads to ducts and alveoli, it will extend over the gland and the lumina. As a result, alveoli will be filled up with harmful exudate. This is apparently the most plausible explanation for the tissue damage observed during E. coli mastitis. Gelatinases, especially milk matrix metalloproteinases (MPP), that are known to be involved in the degradation of the blood-milk barrier, increase massively in the exudate during LPS-induced mastitis. The major source of MPP originates from the neutrophils and the MPP changes are concordant with the increase in SCC during mastitis [193]. I.M. infusion of $10^{8}$ intact or lysed PMN caused palpable signs of inflammation for $24 \mathrm{~h}$ and leukocytosis for 5 days [110]. A mammary explant model was developed to assess mammary tissue damage caused by normal PMN function [38]. Tissue from the udder of lactating Holsteins was cultured in the presence of intact or lysed PMN. PMN that were allowed to phagocytose opsonised zymosan were used. The observed cytological damage included cell sloughing from the basement membrane, pyknosis, cell debris in luminal areas and epithelial vacuolation. The damage to mammary epithelium caused by these treatments was ranked as follows: phagocytosing PMN > lysed PMN > intact PMN.

To study the underlying pathway of tissue damage caused by migrating neutrophils during coliform mastitis (intratissular vs. intraluminal) in vitro studies with primary cell lines and MAC-T cells have been used. Although the in vitro studies are challenging and promising for detailed research, careful interpretation is needed not to oversimplify the phenomenon when extrapolating the results to the in vivo mastitis situation where massive neutrophil diapedesis occurs and where many local physiological homeostatic mechanisms are drastically altered. For example, from both field and experimental studies where E. coli was infused I.M. in cows, there is the wellknown experience that sometimes red blood cells can appear in the milk of the inflamed quarters as a result of the dramatic alteration in mammary blood flow and microvascular integrity during mastitis [245].

\subsection{Cytotoxic mediators}

Three groups of mediators have been studied and attempts were made to dissociate these factors to assess their individual potential for damaging the mammary epithelium. (1) Antibacterial defence involves activation of neutrophils generating ROS capable of killing bacteria [91]. It was observed that neutrophils promote tissue injury and disturb mammary function via ROS production. Host lipid peroxidation, initiated by enzymes such as NADPH oxidase and myeloperoxidase, occurs [260]. (2) Neutrophilic degranulation, during which 
release of proteases occurs as a result of neutrophil trafficking or as a consequence of their phagocytic activity, was also shown to be cytotoxic $[2,22,38,135,165$, 172]. During phagocytosis lysosomes migrate toward the particle being internalised and lysosomal enzymes are released before fusion of the pseudopodia is completed, resulting in the release of lysosomal contents to the outside of the PMN [81]. (3) Brooker et al. [26] postulated that at least two bacterial toxins are involved in E. coli mastitis. I.M. administration of purified commercial LPS (Boivin extraction) produced an intense inflammatory reaction without any epithelial lesion. Neutrophils appeared all over the surface but were not associated with lesions. A fresh filtrate of the medium in which E. coli was growing during $18 \mathrm{~h}$, elicited a mild inflammatory response but scanning electron microscopic examination showed that there was extensive damage of the lining epithelium. Both layers of the epithelium of the lactiferous sinus were lost four hours after infusion. The basement membrane was exposed at that time and by four hours neutrophils also started to appear at the lesions. The postulated cytotoxic agent was not identified but was found to be heat labile. The extensive damage to the ductular epithelium is presumably induced by the unknown cytotoxic compound, produced by $E$. coli. It was further postulated that the damage to the alveolar epithelium may not have the same genesis [79]. For the most severe cases, where all lactiferous sinus epithelia are lost and where interstitial tissue became totally haemorrhagic [97] it was postulated that the LPS molecule might be responsible for the profound circulatory disturbances [79].

In a recent study, LPS and PMA were not found to be toxic to MAC-T cells, whereas the amino acid histidine $(\geq 6 \mathrm{mg} / \mathrm{mL})$ was found to be toxic to mammary secretory epithelial cells. Together, histidine and 500000 activated $\mathrm{PMN} / \mathrm{mL}$ were also toxic [135]. As a consequence, the effect of antioxidants was investigated on the neutrophil induced epithelial damage in vitro. The model consisted of a co-culture of MAC-T cells with isolated bovine neutrophils. PMA-activated neutrophils in combination with $E$. coli endotoxins caused release of superoxide. Epithelial damage was also observed [22, 135]. Melatonin that scavenges hydroxyl radicals and peroxynitrite reduced neutrophil-induced cytotoxicity dose-dependently [22].

\subsection{Effect of rbST on milk loss during mastitis}

The above mentioned findings inspired investigators to evaluate the potential protective effects of recombinant bovine somatotropin (rbST) during coliform mastitis, because during this disease the neutrophil plays a pivotal role in its outcome [244]. In a first study, 19 cows, classified as moderate or severe responders (based on the respiratory burst activity of blood neutrophils before challenge), were treated with rbST or vehicle, $48 \mathrm{~h}$ after I.M. inoculation of E. coli. Clinical status and changes in milk production and composition were compared in the four groups. In a second study, 8 cows received rbST or vehicle 7 days before bacterial challenge. The decrease in milk synthesis was accompanied by increased milk sodium and chloride and decreased potassium and lactose concentrations (Fig. 7, [29]). The latter indicates the opening of tight junctions between mammary epithelial cells, which occurs during inflammation of the mammary gland of ruminants [28]. The decrease in lactose concentration is also the result of its altered synthesis which is, in part, due to the decreased synthesis of $\alpha$-lactalbumin [93]. Milk production of rbST cows recovered better than that of placebo cows. Recovery of milk components, such as lactose (Fig. 7), was accelerated in severe responders treated with rbST, but not in moderate responders. Pre-treatment of severe responders with rbST enhanced milk production before infection, protected the mammary glands from excessive loss 


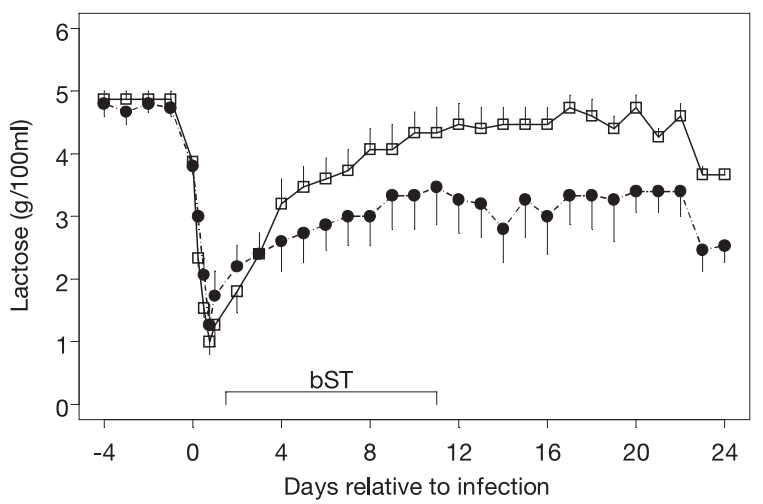

Figure 7. Milk lactose concentrations in infected quarters of $\operatorname{rbST}$ treated $(\bullet, n=7)$ and control $(\square$, $n=10$ ) cows with acute $E$. coli mastitis in early lactation. (Figure taken from the original paper [29], with permission.)

of milk during the subsequently induced coliform mastitis, and accelerated normalisation of milk composition. It was concluded that: (1) the beneficial effects of rbST upon normalisation of milk production and composition was restricted to severe responders; (2) the beneficial effects of the treatment with rbST was most pronounced on milk composition in infected glands. The acceleration of the tightening of the blood-milk barrier was spectacular; the gain in milk production was less pronounced. This might suggest that rbST (or IGF-I) increases milk production in the diseased gland, partly by inhibiting epithelial cell loss and/or restoring cellular differentiation. In a T84 cell monolayer model it was demonstrated that IGF-I and IGF-II regulate the paracellular permeability through a receptor-mediated process that probably involves changes in protein synthesis and cytoskeletal structure [155]. (3) In severe responders that had been treated with rbST, changes observed during mastitis resembled those in moderate responders treated with the placebo. The exact mechanism of how rbST affects the recovery of the secretory epithelium during mastitis remains unknown. During coliform mastitis bST concentration is higher in challenged cows, IGF-I increases in whey of the infected glands [34, 209], and IGF binding proteins also increase in the whey of infected glands [209]. The endogenous release of bST and IGF-I during mastitis might be considered as a homeostatic mechanism involved in the resolution of the inflammatory response. It is also possible that rbST increased the rate of cell renewal in the lactating mammary gland as it does during normal lactation [39]. The rbST or its intermediary IGF that increases in milk whey during mastitis, may have interfered with apoptotic factors that are released during mastitis and that induce cell death. It is also not excluded that rbST may have had an indirect effect on mastitis through enhancing the defence system of the cow [34]. Elvinger et al. [71] showed that administration of $\mathrm{rbST}$ to cows increased lymphocyte blastogenesis but not phagocytosis and killing of E. coli by PMN. Recombinant human growth hormone primes human neutrophils for enhanced superoxide anion secretion [80].

The possible effect of rbST was also studied during $S$. uberis mastitis, another environmental mastitis type. Cows were treated with long acting rbST 7 days before 
and after infection and compared with control cows that received the excipient. Comparable results were obtained. Somatotropin protected the mammary gland from excessive production losses. It also significantly improved the normalisation of composition, indicating a beneficial effect on the restoration of the integrity of the blood-milk barrier [100]. Also in this model, rbST treatment induced significantly higher IGF-I and rbST concentrations in plasma. Despite these positive effects on milk production and composition, no effect on some defence parameters such as chemiluminescence, rate of diapedesis and the expression of adhesion receptors of circulating PMN could be detected [99].

\subsection{Lesions in rare cases of atypical E. coli mastitis}

The pathogenesis of atypical cases of E. coli mastitis falls beyond the scope of this review. It is however interesting to focus on some particular characteristics. Sometimes a delayed PMN infiltration results in a failure to eliminate the bacteria. Pathogens and PMN co-exist for many days, with a gradual increase in the proportion of mononuclear cells in the secretion, which are themselves less efficient at killing bacteria [48]. In these cases dramatic epithelial hyperplasia occurs. The secretory function of the gland is lost or severely impaired. Two strains of E. coli, isolated from the milk of two different cows suffering from persistent $E$. coli mastitis were tested for adhesion to and invasion of three primary mammary epithelial cell cultures derived from mammary biopsies of the two infected cows. Here, intracellular E. coli were detected during five days post-infection in vitro. Histology of mammary tissue revealed chronic inflammatory changes in quarters that were persistently infected by $E$. coli but in contrast to the in vitro situation, intracellular bacteria were not detected in mammary tissue sections [67].

\section{CONCLUSION}

From both epidemiological and experimental studies it can be concluded that severity of coliform mastitis is of much more concern than its incidence. Moreover, from many recent studies it appears that the severity of $E$. coli mastitis is mainly related to "host factors" rather than to the pathogen itself. The periparturient period, the early stage of lactation, parity, hormonal and metabolic alterations, and negative energy balance may affect PMN function and bactericidal efficiency in blood and the mammary gland of the dairy cow. The PMN dysfunction influences the balance between the inflammatory reactions, bactericidal capacity and tissue damage, boosting the severity of $E$. coli mastitis. This dysfunction may originate at the level of the bone marrow, the blood circulation and/ or the mammary gland. In dairy cows the severity of E. coli mastitis is more likely during early lactation and more pronounced in older cows. Any management strategy that aims to influence the severity of $E$. coli mastitis in dairy cows should be focused on both the dry and periparturient period. Moreover, this strategy should be directed towards minimizing energy and environmental stress. Some genetic factors might also be involved temporarily. It is possible that as a result of parturition, negative energy balance, etc., certain genes are (or are not) expressed during the beginning of lactation. Optimisation of the bactericidal capacity of PMN and diminishing tissue damage during E. coli mastitis is a challenge for research in the near future.

\section{ACKNOWLEDGEMENTS}

The authors express sincere thanks to the scientific advisory board and more especially to Director J. Weerts and Mr. X. Van Huffel of DG VI, Ministry of Agriculture, Brussels, for their support in favour of the mastitis research projects executed in Belgium. Many studies mentioned in this review were granted by this 
institution. The authors also gratefully acknowledge the Secretary-General of FWO (Fonds voor Wetenschappelijk onderzoek), Mr. J. Traest and the scientific board the Physiology section for granting the basic research studies in connection with neutrophil function and mastitis.

\section{REFERENCES}

[1] Adler H., Frech B., Thony M., Peterhans E., Jungi T.W., Inducible nitric oxide synthase in cattle. Differential cytokine regulation of nitric oxide synthase in bovine and murine macrophages, J. Immunol. 154 (1995) 47104718.

[2] Akers R.M., Thompson W., Effect of induced leukocyte migration on mammary cell morphology and milk component biosynthesis, J. Dairy Sci. 70 (1987) 1685-1695.

[3] Allen R.C., Stjernholm R.L., Steele R.H., Evidence for the generation of an electronic excitation state(s) in human polymorphonuclear leukocytes and its participation in bactericidal activity, Biochem. Biophys. Res. Commun. 47 (1972) 679-684.

[4] Allen R.C., Dale D.C., Taylor F.B., Blood phagocyte luminescence: gauging systemic immune activation, Methods Enzymol. 305 (2000) 591-629.

[5] Anderson K.L., Kindahl H., Petroni A., Smith A.R., Gustafsson B.K., Arachidonic acid metabolites in milk of cows during acute mastitis, Am. J. Vet. Res. 46 (1985) 15731577.

[6] Anggard E., Nitric oxide: mediator, murderer, and medicine, The Lancet 343 (1994) 1199-1206.

[7] Babior B., The respiratory burst of phagocytes, J. Clin. Invest. 73 (1984) 599-601.

[8] Babior B.M., Activation of the respiratory burst oxidase, Environ. Health Prospect. 102 (1994) 53-56.

[9] Baldridge C.W., Gerard R.W., The extra respiration of phagocytosis, Am. J. Pathol. 103 (1933) 235-236.

[10] Belaaouaj A., McCarthy R., Baumann M., Gao Z., Ley T.J., Abraham S.N., Shapiro S.D., Mice lacking neutrophil elastase reveal impaired host defense against gram-negative bacterial sepsis, Nature 4 (1998) 615-619.

[11] Belaaouaj A., Kim K.S., Shapiro S.D., Degradation of outer membrane protein $\mathrm{A}$ in Escherichia coli killing by neutrophil elastase, Science 289 (2000) 1185-1188.
[12] Berning L.M., Paape M., Peters R.R., Functional variation in endogenous and exogenous immunoglobulin binding to bovine neutrophils relative to parturition, Am. J. Vet. Res. 54 (1993) 1145-1153.

[13] Bertram T.A., Neutrophilic leukocyte structure and function in domestic animal, Adv. Vet. Sci. Comp. Med. 30 (1985) 91-129.

[14] Beutler B., TLR4 as the mammalian endotoxin sensor, Curr. Top. Microbiol. Immunol. 270 (2002) 108-120.

[15] Bishop J.G., Schanbacher F.L., Ferguson L.C., Smith K.L., In vitro growth inhibition of mastitis-causing coliform bacteria by bovine apo-lactoferrin and reversal of inhibition by citrate and high concentrations of apo-lactoferrin, Infect. Immun. 14 (1976) 911-918.

[16] Blum J.W., Dosogne H., Hoeben D., Vangroenweghe F., Hammon H.M., Bruckmaier R.M., Burvenich C., Tumor necrosis factor-alpha and nitrite/nitrate responses during acute mastitis induced by Escherichia coli infection and endotoxin in dairy cows, Domest. Anim. Endocrinol. 19 (2000) 223235.

[17] Bondue H., Machin D., Stryckmans P.A., The leukocyte alkaline phosphatase activity in mature neutrophils of different ages, Scand. J. Haematol. 24 (1980) 51-56.

[18] Born J., Uthgenannt D., Dodt C., Nunninghoff D., Ringvolt E., Wagner T., Fehm H.-L., Cytokine production and lymphocyte subpopulations in aged humans. An assessment during nocturnal sleep, Mech. Ageing Dev. 84 (1995) 113-126.

[19] Bouchard L., Blais S., Desrosiers C., Zhao X., Lacasse P., Nitric oxide production during endotoxin-induced mastitis in the cow, $\mathrm{J}$. Dairy Sci. 82 (1999) 2574-2581.

[20] Boudjellab N., Chan-Tang H.S., Zhao X., Bovine interleukin-1 expression by cultured mammary epithelial cells (MAC-T) and its involvement in the release of MAC-T derived interleukin-8, Comp. Biochem. Physiol. A. Mol. Integr. Physiol. 127 (2000) 191-199.

[21] Boulanger V., Bouchard L., Zhao X., Lacasse P., Induction of nitric oxide production by bovine mammary epithelial cells and blood leukocytes, J. Dairy Sci. 84 (2001) 14301437.

[22] Boulanger V., Zhao X., Lacasse P., Protective effect of melatonin and catalase in bovine neutrophil-induced model of mammary cell damage, J. Dairy Sci. 85 (2002) 562-569. 
[23] Bramley A.J., King J.S., Higgs T.M., Neave F.K., Colonization of the bovine duct following inoculation with Staphylococcus areus and Escherichia coli organisms at or into the teat duct, Br. Vet. J. 135 (1979) 149-162.

[24] Bramley A.J., Scientific summary of the Ghent meeting, in: Burvenich C., VandeputteVan Messom G., Hill A.W. (Eds.), New insights into the pathogenesis of mastitis, Flemish Veterinary Journal, Merelbeke, Belgium, 1991, pp. 235-238.

[25] Briheim G., Stendhal O., Dahlgren C., Intraand extracellular events in luminol-dependent chemiluminescence of polymorphonuclear leukocytes, Infect. Immun. 45 (1984) 1-5.

[26] Brooker B.E., Frost A.J., Hill A.W., At least two toxins are involved in Escherichia coli mastitis, Experientia 37 (1981) 290-292.

[27] Burvenich C., Peeters G., Effect of prostaglandin synthetase inhibitors on mammary blood flow during experimentally induced mastitis in lactating goats, Arch. Int. Pharmacodyn. Thér. 258 (1982) 128-137.

[28] Burvenich C., Peeters G., Effect of experimentally induced mastitis on blood flow in the heterolateral gland in lactating goats, Zentrbl. Vetmed. Reihe A 30 (1983) 459469.

[29] Burvenich C., Vandeputte-Van Messom G., Roets E., Massart-Leën A.-M., Akers R.M., Reynaert-Van Sichem R., Devriese L., Hormone somatotropine bovine et mammite aiguë à Escherichia coli, Ann. Méd. Vét. 132 (1988) 601-606.

[30] Burvenich C., Heyneman R., Fabry J., Vandeputte-Van Messom G., Massart-Leën A.-M., Roets E., Possible role for bovine somatotropin (BST) during the recovery of experimentally induced $E$. coli mastitis in cows soon after parturition, Proceedings International Conference on Mastitis, St. Georgen/Sängsee Kärnten, Austria, 1989, pp. 4-9.

[31] Burvenich C., Paape M.J., Hill A.W., Guidry A.J., Miller R.H., Heyneman R., Kremer W.D.J., Brand A., Role of neutrophil leukocyte in the local and systemic reactions during experimentally induced Escherichia coli mastitis in cows immediately after calving, Vet. Q. 16 (1994) 45-50.

[32] Burvenich C., Guidry A.J., Paape M., MassartLeën A.M., Defence mechanisms of the lactating and dry mammary gland, in: Proceeding of the 3rd International Mastitis Seminar, Telaviv, Israel, 1995.

[33] Burvenich C., Dosogne H., Detilleux J., Van Werven T., Is it possible to predict the severity of acute mastitis during early lactation through measurement of the activity of circulating polymorphonuclear cells?, in: Proceedings of Journées Nationales GTV-INRA, Nantes, France, 1999, pp. 43-52.

[34] Burvenich C., Paape M.J., Hoeben D. Dosogne H., Massart-Leën A.-M., Blum J., Modulation of the inflammatory reaction and neutrophil defense of the bovine lactating mammary gland by growth hormone, Domest. Anim. Endocrinol. 17 (1999) 149-159.

[35] Butcher S., Chahel H., Lord J.M., Ageing and the neutrophil: no appetite for killing? Immunology 100 (2000) 411-416.

[36] Callery M.P., Kamei T., Mangino M.J., Flye M.W., Organ interactions in sepsis. Host defense and hepatic-pulmonary macrophage axis, Arch. Surg. 126 (1991) 28-32.

[37] Cannon W.B., La sagesse du corps (traduit de l'anglais par Z.M.Bacq), Paris, France, 1946.

[38] Capuco A.V., Paape M.J., Nickerson S.C., In vitro study of polymorphonuclear leukocyte damage to mammary tissues of lactating cows, Am. J. Vet. Res. 47 (1986) 663-668.

[39] Capuco A.V., Long E., Wood D.L., Sonstegard T., Tomita G., Paape M.J., Zhao X., Escherichia coli induces apoptosis and proliferation of mammary cells, Cell Death Differ. 8 (2001) 808-816.

[40] Carreras M.C., Pargament G.A., Catz S.D., Poderoso J.J., Boveris A., Kinetics of nitric oxide and hydrogen peroxide production and formation of peroxynitrite during the respiratory burst of human neutrophils, FEBS 341 (1994) 65-68.

[41] Carroll E.J., Schalm O.W., Lasmanis J., Experimental coliform (Aerobacter aerogenes) mastitis: characteristics of the endotoxin and its role in pathognesis, Am. J. Vet. Res. 25 (1964) 663-668.

[42] Cebra C.K., Garry F.B., Dinsmore R.P., Naturally occurring acute coliform mastitis in Holstein cattle, J. Vet. Internal Med. 10 (1996) 252-257.

[43] Cepinskas G., Sanding M., Kvietys P.R., PAF-induced elastase dependent neutrophil transendothelial migration is associated with the mobilization of elastase to the neutrophil surface and localization to the migrating front, J. Cell Sci. 112 (1999) 1937-1945.

[44] Chapman A.L.P., Hampton M.B., Senthilmohan R., Winterbourn C.C., Kettle A.J., Chlorination of bacterial and neutrophil proteins during phagocytosis and killing of Staphylococcus aureus, J. Biol. Chem. 227 (2002) 97579762 . 
[45] Chatta G.S., Andrews R.G., Rodger E., Schrag M., Hematopoietic progenitors and aging: alterations in granulocyte precursors and responsiveness to recombinant human G-CSF, GM-CSF and IL-3, J. Gerontol. 48 (1993) M207-M212.

[46] Chen A., Engel P., Tedder T.F., Structural requirements regulate endoproteolytic release of L-selectin (CD62L) adhesion receptor from the cell surface of leukocytes, J. Exp. Med. 182 (1995) 519-530.

[47] China B., Goffaux F., Secretion of virulence factors by Escherichia coli, Vet. Res. 30 (1999) 181-202.

[48] Craven N., Anderson J.C., Phagocytosis of Staphylococcus aureus by bovine mammary gland macrophages and intracellular protection from antibiotic action in vitro and in vivo, J. Dairy Res. 51 (1984) 513-523.

[49] DeChatelet R.L., Gwynn D.L., Shirley P.S., Bass D.A., Thomas M.J., Henderson F.W., Cohen M.S., Mechanism of the luminoldependent chemiluminescence of human neutrophils, J. Immunol. 129 (1982) 1589 1593.

[50] Deluyker H.A., Milk yield fluctuations associated with mastitis, in: Burvenich $\mathrm{C}$. Vandeputte-Van Messom G., Hill A.W. (Eds.), New insights into the pathogenesis of mastitis, Flemish Veterinary Journal, Merelbeke, Belgium, 1991, pp. 207-216.

[51] Detilleux J.C., Genetic factors affecting susceptibility of dairy cows to udder pathogens, Vet. Immunol. Immunopathol. 88 (2002) $103-110$.

[52] Detilleux J.C., Koehler K.J., Freeman A.E.F., Kehrli M.E.J., Kelly D.H., Immunological parameters of periparturient Holstein cattle: Genetic variation, J. Dairy Sci. 77 (1994) 2640-2645.

[53] Dhondt G., Burvenich C., Peeters G., Mammary blood flow during experimental Escherichia coli endotoxin induced mastitis in goats and cows, J. Dairy Res. 44 (1977) $433-440$

[54] DiCarlo A.L., Paape M., Miller R.H., Reactivity of purified complement component $3 b$ with bovine neutrophils and modulation of complement receptor 1, Am. J. Vet. Res. 57 (1996) 151-156.

[55] Diez-Fraile A., Tomita G.M., Meyer E., Paape M.J., Burvenich C., CD62L expression on circulating neutrophils in relation to Escherichia coli mastitis, in: Zecconi A. (Ed.), Proceedings of the International Dairy Federation Symposium on Immunology of the Ruminant Mammary Gland, 2000, pp. 177-178.
[56] Diez-Fraile A., Meyer E., Burvenich C., Regulation of adhesion molecules on circulating neutrophils during coliform mastitis and their possible immunomodulation with drugs, Vet. Immunol. Immunopathol. 86 (2002) 1-10.

[57] Diez-Fraile A., Meyer E., Burvenich C., Sympathoadrenal and immune system activation during the periparturient period and their association with bovine coliform mastitis. A review, Vet. Q. 25 (2003) 31-44.

[58] Ditcham W.G.F., Leigh J.A., Bland A.P., Hill A.W., Adhesion of Streptococcus uberis to monolayers of cultured epithelial cells derived from the bovine mammary gland, FEMS Immunol. Med. Microbiol. 14 (1996) $145-150$

[59] Dosogne H., Burvenich C., Van Werven T., Roets E., Noordhuizen-Stassen E.N., Goddeeris B., Increased surface expression of $\mathrm{CD} 11 \mathrm{~b}$ receptors on PMN is not sufficient to sustain phagocytosis during Escherichia coli mastitis in early postpartum dairy cows, Vet. Immunol. Immunopathol. 60 (1997) 47-59.

[60] Dosogne H., Capuco A.V., Paape M., Roets E., Burvenich C., Fenwick B., Reduction of acyloxyacyl hydrolase activity in circulating neutrophils from cows after parturition, $\mathrm{J}$. Dairy Sci. 81 (1998) 672-677.

[61] Dosogne H., Burvenich C., Freeman A.E. Kehrli M.E.J., Detilleux J., Sulón J., Beckers J.-F., Hoeben D., Pregnancy-associated glycoprotein and decreased polymorphonuclear leukocyte function in early post-partum dairy cows, Vet. Immunol. Immunopathol. 67 (1999) 47-54.

[62] Dosogne H., Massart-Leën A.-M., Burvenich C., Immunological aspects of pregnancyassociated glycoproteins, Adv. Exp. Med. Biol. 480 (2000) 295-305.

[63] Dosogne H., Vangroenweghe F., Barrio B., Rainard P., Burvenich C., Decreased number and bactericidal activity against Staphylococcus aureus of the resident cells in milk of dairy cows during early lactation, J. Dairy Res. 68 (2001) 539-549.

[64] Dosogne H., Meyer E., Sturk A., van Loon J., Massart-Leën A.-M., Burvenich C., Effect of enrofloxacin treatment on plasma endotoxin during bovine Escherichia coli mastitis, Inflammation Res. 51 (2002) 201-205.

[65] Dosogne H., Vangroenweghe F., Burvenich C., Potential mechanism of action of J5 vaccine in protection against severe bovine coliform mastitis, Vet. Res. 33 (2002) 1-12.

[66] Döpfer D., Almeida R.A., Lam T.J., Nederbrag H., Oliver S.P., Gaastra W., Adhesion and invasion of Escherichia coli from single and 
recurrent clinical cases of bovine mastitis in vitro, Vet. Microbiol. 74 (2000) 331-343.

[67] Döpfer D., Nederbragt H., Almeida R.A., Gaastra W., Studies about the mechanism of internalization by mammary epithelial cells of Escherichia coli isolated from persistent bovine mastitis, Vet. Microbiol. 80 (2001) 285-296.

[68] Eberhart R.J., Coliform mastitis, J. Am. Vet. Med. Assoc. 170 (1977) 1160-1163.

[69] Edwards S.W., Swan T.F., Regulation of superoxide generation by myeloperoxidase during the respiratory burst of human neutrophils, Biochem. J. 237 (1986) 601-604.

[70] Elsbach P., Weiss J., Franson R.C., BeckerditeQuagliata S., Schneider A., Harris L., Separation and purification of a potent bactericidal/ permeability-increasing protein and a closely associated phospholipase A2 from rabbit polymorphonuclear leukocytes. Observations on their relationship, J. Biol. Chem. 254 (1979) 11000-11009.

[71] Elvinger F., Hansen P.J., Head H.H., Natzke R.P., Actions of bovine somatotropin on PMN and lymphocytes in cattle, J. Dairy Sci. 74 (1991) 2145-2152.

[72] Faris A., Krovacek K., Fröman G., Wadström T., Binding of fibronectin to Escherichia coli isolated from mastitis from different geographical regions, Vet. Microbiol. 15 (1987) 129-136.

[73] Faulkner K., Fridovich I., Luminol and lucigenin as detectors for $\mathrm{O}_{2}^{-}$, Free Radic. Biol. Med. 15 (1993) 447-451.

[74] Feng D., Nagy J., Pyne K., Dvorak H.F., Dvorak A.M., Neutrophils emigrate from venules by a transendothelial cell pathway in response to FMLP, J. Exp. Med. 187 (1998) 903-915.

[75] Fenwick B.W., Virulence attributes of the liposaccharides of the HAP group organisms, Can. J. Vet. Res. 54 (1990) S28-S32.

[76] Frost A.J., Selective adhesion of microorganisms to the ductular epithelium of the bovine mammary gland, Infect. Immun. 12 (1975) 1154-1156.

[77] Frost A.J., Hill A.W., Brooker B.E., The early pathogenesis of bovine mastitis due to Escherichia coli, Proc. R. Soc. Lond. B Biol. Sci. 209 (1980) 419-431.

[78] Frost A.J., Hill A.W., Brooker B.E., Pathogenesis of experimental bovine mastitis following a small inoculum of Escherichia coli, Res. Vet. Sci. 23 (1982) 105-112.

[79] Frost A.J., Brooker B.E., Hyperacute Escherichia coli mastitis of cattle in the immediate post-partum period, Aust. Vet. J. 63 (1986) 327-331.

[80] Fu Y.K., Arkins S., Fuh G., Cunningham B.C., Wells J.A., Fong S., Cronin M.J., Dantzer R., Kelley K.W., Growth hormone augments superoxide anion secretion of human neutrophils by binding to the prolactin receptor, J. Clin. Invest. 89 (1992) 451-457.

[81] Gennaro R.B., Dewald B., Horisberger U., Gubler H.U., Baggiolini M.A., A novel type of cytoplasmic granule in bovine neutrophils, J. Cell Biol. 96 (1983) 1651-1661.

[82] Ginzberg H.H., Cherapanov V., Dong Q., Cantin A., McCulloh C.A., Shannon P.T., Downey G.P., Neutrophil-mediated epithelial injury during transmigration: role of elastase, Am. J. Physiol. Gastrointest. Liver Physiol. 281 (2001) G705-G717.

[83] Glasser L., Fiederlein R.L., Functional differentiation of normal human neutrophils, Blood 69 (1987) 937-944.

[84] Grebner J.V., Mills E.L., Gray B.H., Quie P.G., Comparison of phagocytic and chemiluminescence response of human polymorphonuclear neutrophils, J. Lab. Clin. Med. 89 (1977) 153-159.

[85] Green M.J., Green L.E., Cripps P.J., Low bulk milk somatic cell counts and endotoxinassociated (toxic) mastitis, Vet. Rec. 138 (1996) 305-306.

[86] Griffin F.M.J., Griffin J.A., Leider J.E., Silverstein S.C., Studies on the mechanism of phagocytosis. I. Requirements for circumferential attachment of particle-bound ligands to specific receptors on the macrophage plasma membrane, J. Exp. Med. 142 (1975) 12631282.

[87] Guidry A.J., Paape M.J., Pearson R.E., Effects of estrus and exogenous estrogen on circulating neutrophils and milk somatic cell concentration, neutrophil phagocytosis, and occurrence of clinical mastitis in cows, Am. J. Vet. Res. 36 (1975) 1555-1560.

[88] Guidry A.J., Paape M.J., Effect of bovine neutrophil maturity on phagocytosis, Am. J. Vet. Res. 37 (1976) 703-705.

[89] Hakogi E., Tamura H., Tanaka S., Kohata A., Shimada Y., Tabuchi K., Endotoxin levels in milk and plasma of mastitis-affected cows measured with a chromogenic limulus test, Vet. Microbiol. 20 (1989) 267-274.

[90] Hampton M.B., Chambers S.T., Vissers M.C., Winterbourn C.C., Bacterial killing by neutrophils in hypertonic environments, $\mathbf{J}$. Infect. Dis. 169 (1994) 839-846.

[91] Hampton M.B., Kettle A.J., Winterbourn C.C., Inside the neutrophil phagosome: oxidants, myeloperoxidase, and bacterial killing, Blood 92 (1998) 3007-3017. 
[92] Hartman I., Ziv G., Saran A., Application of the Limulus amoebocyte lysate test to the detection of gram-negative bacterial endotoxins in normal and mastitic milk, Res. Vet. Sci. 20 (1976) 342-343.

[93] Heyneman R., Burvenich C., Vercauteren $\mathrm{R}$., Interaction between the respiratory burst activity of neutrophil leukocytes and experimentally induced $E$. coli mastitis in cows, J. Dairy Sci. 73 (1990) 985-994.

[94] Heyneman R., Burvenich C., Kinetics and characteristics of bovine neutrophil alkaline phosphatase during acute Escherichia coli mastitis, J. Dairy Sci. 75 (1992) 1826-1834.

[95] Hill A.W., Shears A.L., Hibbitt K.G., The pathogenesis of experimental Escherichia coli mastitis in newly calved dairy cows, Res. Vet. Sci. 26 (1979) 97-101.

[96] Hill A.W., Factors influencing the outcome of Escherichia coli mastitis in the dairy cow, Res. Vet. Sci. 31 (1981) 107-112.

[97] Hill A.W., Somatic cells - Friends or foes? in: Burvenich C., Vandeputte-Van Messom G., Hill A.W. (Eds.), New insights into the pathogenesis of mastitis, Flemish Veterinary Journal, Merelbeke, Belgium, 1991, pp. 217-232.

[98] Hirvonen J., Eklund K., Teppo A.M., Huszenicza G., Kulcsar M., Saloniemi H. Pyörälä S., Acute phase response in dairy cows with experimentally induced Escherichia coli mastitis, Acta Vet. Scand. 40 (1999) 35-46.

[99] Hoeben D., Burvenich C., Eppard P.J., Byatt J.C., Hard D.L., Effect of recombinant bovine somatotropin on neutrophil functions and clinical symptoms during Streptococcus uberis mastitis, J. Dairy Sci 82 (1999) 14651481.

[100] Hoeben D., Burvenich C., Eppard P.J., Hard D.L., Effect of recombinant bovine somatotropin on milk production and composition in bovine Streptococcus uberis mastitis, J. Dairy Sci. 82 (1999) 1671-1683.

[101] Hoeben D., Burvenich C., Massart-Leën A.-M., Lenjou M., Nijs G., Van Bockstaele D., Beckers J.-F., In vitro effect of ketone bodies, glucocorticosteroids and bovine pregnancy-associated glycoprotein on cultures of bone marrow progenitor cells of cows and calves, Vet. Immunol. Immunopathol. 68 (1999) 229-240.

[102] Hoeben D., Burvenich C., Trevisi E., Bertoni G., Hamann J., Bruckmaier R.M., Blum J., Role of endotoxin and TNF- $\alpha$ in the pathogenesis of experimentally induced coliform mastitis in periparturient cows, J. Dairy Res. 67 (2000) 503-514
[103] Hoffstein S., Goldstein I.M., Weissmann G., Role of microtubule assembly in lysosomal enzyme secretion from human polymorphonuclear leukocytes, J. Cell Biol. 73 (1977) 242-256.

[104] Hogan J.S., Smith K.L., Hoblet K.H., Schoenberger P.S., Todhunter D.A., Hueston W.D., Pritchard D.E., Bowman G.L., Heider L.E., Brockett B.L., Field survey of clinical mastitis in low somatic cell count herds, J. Dairy Sci. 72 (1989) 1547-1556.

[105] Hogan J.S., Weiss W.P., Smith K.L., Role of vitamin $\mathrm{E}$ and selenium in host defense against mastitis, J. Dairy Sci. 76 (1993) $2795-2803$

[106] Huber D., Balda M.S., Matter K., Occludin modulates transepithelial migration of neutrophils, J. Biol. Chem. 275 (2000) 57735778.

[107] Huynh H.T., Robitaille G., Turner J.D., Establishment of bovine epithelial cells (MAC-T): an in vitro model for bovine lactation, Exp. Cell. Res. 197 (1991) 191-199.

[108] Inoue T., Saito H., Matsuda T., Fukatsu K. Han I., Furukawa S., Ikeda S., Muto T., Growth hormone and insulin-like growth factor I augment bactericidal capacity of human polymorphonuclear neutrophils, Shock 10 (1998) 278-284.

[109] Jackson E.R., Bramley A.J., Coliform mastitis, In Pract. 5 (1983) 135-146.

[110] Jain N.C., Schalm O.W., Carroll E.J., Lasmanis J., Leukocytes and tissue factors in the pathogenesis of bovine mastitis, Am. J. Vet. Res. 33 (1972) 1137-1145.

[111] Jankowski A., Scott C.C., Grinstein S., Determinants of phagosomal $\mathrm{pH}$ in neutrophils, J. Biol. Chem. 277 (2002) 60596066.

[112] Jones T.Q., Escherichia coli mastitis in dairy cattle - A review of the literature, Vet. Bull. 60 (1990) 205-220.

[113] Jubb K.V.F., Kennedy P.C., Pathology of domestic animals, Academic Press, New York, USA, 1975.

[114] Jungi T.W., Nitric oxide synthesis by macrophages: a lesson learned from ruminants, Curr. Trends Immunol. 1 (1998) 1-10.

[115] Kahl S., Elsasser T.H., Blum J., Nutritional regulation of plasma tumor necrosis factoralpha and plasma and urinary nitrite/nitrate responses to endotoxin in cattle, Proc. Soc. Exp. Biol. Med. 215 (1997) 370-376.

[116] Kaneene J.B., Miller R., Herdt T.H., Gardiner J.C., The association of serum 
nonesterified fatty acids and cholesterol, management and feeding practices with peripartum disease in dairy cows, Prev. Vet. Med. 31 (1997) 59-72.

[117] Karlsson A., Nixon J.B., Mcphail L.C., Phorbol myristate acetate induces neutrophils NADPH-oxidase activity by two separate signal transduction pathways: dependent or independent of phosphatidylinositol 3-kinase, J. Leukoc. Biol. 67 (2000) 396-404.

[118] Katoh M., Shirai T., Shikoshi K., Ishii M., Saito M., Kitagawa S., Neutrophil kinetics shortly after initial administration of recombinant human granulocyte colony-stimulating factor: neutrophil alkaline phosphatase activity as an endogenous marker, Eur. J. Haematol. 49 (1992) 19-24.

[119] Kehrli M.E.J., Harp J.A., Immunity in the mammary gland, Vet. Clin. N. Am.: Food Anim. Pract. 17 (2001) 495-516.

[120] Keleman E., Granulocyte alkaline phosphatase activity: a measure of the emergence time of mature marrow neutrophils?, Acta Haematol. 50 (1973) 19-24.

[121] Kelm S.C., Detilleux J.C., Freeman A.E., Kehrli M.E.J., Dietz A.B., Fox L.K., Butler J.E., Kasckovics I., Kelley D.H., Genetic association between parameters of innate immunity and measures of mastitis in periparturient holstein cattle, J. Dairy Sci. 80 (1997) 1767-1775.

[122] Kirkwood T.B.L., Human senescence, Bioessays 18 (1996) 1009-1016.

[123] Kornalijnslijper J.E., Van Werven T., Daeman A.J., van den Broek J., Niewold T.A., Rutten V.P., Noordhuizen-Stassen E.N., In vitro growth of mastitis-inducing Escherichia coli in milk and milk fractions of dairy cows, Vet. Microbiol. 91 (2003) 125-134.

[124] Kremer W.D.J., Noordhuizen-Stassen E.N., Grommers F.J., Daemen A.J.J.M., Brand A., Burvenich C., Blood polymorphonuclear leukocyte chemotaxis during experimental Escherichia coli bovine mastitis, J. Dairy Sci. 76 (1993) 2613-2618.

[125] Kremer W.D.J., Noordhuizen-Stassen E.N., Grommers F.J., Daemen A.J.J.M., Henricks P.A.J., Brand A., Burvenich C., Preinfection chemotactic response of blood PMN to predict severity of Escherichia coli mastitis, J. Dairy Sci. 76 (1993) 1568-1574.

[126] Kremer W.D.J., Noordhuizen-Stassen E.N., Grommers F.J., Schukken Y.H., Heeringe R., Brand A., Burvenich C., Severity of experimental Escherichia coli mastitis in ketonemic and nonketonemic dairy cows, J. Dairy Sci. 76 (1993) 3428-3436.
[127] Kubo K., Kamada T., Okamoto H., Izumi Y., Otsuji S., Sueda T., Lipopolysaccharide increases cell surface-associated fibronectin in fibroblasts in vitro, Oral Microbiol. Immunol. 11 (1996) 29-34.

[128] Kurek C., Presence of coryneform organisms (C) in cow udders. III. Fermentation and hemagglutination properties as well as pathogenicity of C. uberis, Pol. Arch. Weter. 18 (1975) 53-62.

[129] Kurt-Jones E.A., Mandell L., Whitney C., Padgett A., Gosselin K., Newburger P.E., Finberg R.W., Role of toll-like receptor 2 (TLR2) in neutrophil activation: GM-CSF enhances TLR2 expression and TLR2-mediated interleukin 8 responses in neutrophils, Blood 100 (2002) 1860-1868.

[130] Kwon N.S., Nathan C.F., Stuerh D.J., Reduced biopterin as a cofactor in the generation of nitrogen oxides by murine macrophages, J. Biol. Chem. 264 (1989) 2049620501.

[131] Lam T.J.G.M., Van Vliet J.H., Schukken Y.H., Grommers F.J., Van Velden-Russcher A., Barkema H.W., Brand A., The effect of discontinuation of postmilking teat disinfection in low SCC herds. 1. Incidence of clinical mastitis, Vet. Q. 19 (1997) 41-47.

[132] Lammers A., Nuijten P.J., Kruijt E., StockhofeZurwieden N., Vacht U., Smith H.E., van Zijderveld F.G., Cell tropism of Staphylococcus aureus in bovine mammary gland cell cultures, Vet. Microbiol. 67 (1999) 77-89.

[133] Lammers A., van Vorstenbosch C.J., Erkens J.H., Smith H.E., The major bovine mastitis pathogens have different cell tropisms in cultures of bovine mammary gland cells, Vet. Microbiol. 80 (2001) 255-265.

[134] Lang C.H., Bagby G.J., Dobrescu C., Nelson S., Spitzer J.J., Effect of granulocyte colonystimulating factor on sepsis-induced changes in neutrophil accumulation and organ glucose uptake, J. Infect. Dis. 166 (1992) 336343.

[135] Ledbetter T.K., Paape M.J., Douglass L.W., Cytotoxic effects of peroxynitrite, polymorphonuclear neutrophils, free-radical scavengers, inhibitors of myeloperoxidase, and inhibitors of nitric oxide synthase on bovine mammary secretory epithelial cells, Am. J. Vet. Res. 62 (2001) 286-293.

[136] Lee S.U., Quesnell M., Fox L.K., Yoon J.W., Park Y.H., Davis W.C., Falk D., Deobald C.F., Bohach G.A., The early pathogenesis of bovine mastitis due to Escherichia coli, Proc. R. Soc. Lond. B Biol. Sci. 61 (1980) 431-439. 
[137] Leininger D.J., Roberson J.R., Elvinger F., Ward D., Akers R.M., Evaluation of frequent milkout for treatment of cows with experimentally induced Escherichia coli mastitis, J. Am. Vet. Med. Assoc. 222 (2003) 63-66.

[138] Leino L., Paape M.J., Comparison of the chemiluminescence responses of bovine neutrophils to differently opsonized zymosan particles, Am. J. Vet. Res. 54 (1993) 10551059.

[139] Levy R., Dana R., Gold B., Alkan M., Schlaeffer F., Influence of calcium channel blockers on polymorphonuclear and monocyte bactericidal and fungicidal activity, Isr. J. Med. Sci. 27 (1991) 301-306.

[140] Lichtman M.A., Cellular deformability during maturation of the myeloblast: possible role in marrow egress, N. Engl. J. Med. 283 (1970) 943-948.

[141] Lichtman M.A., Weed R.I., Alterations of the cell periphery during granulocyte maturation: relationship to cell function, Blood 39 (1972) 301-309.

[142] Lind J., Merenyi G., Eriksen T.E., Chemiluminescence mechanism of cyclic hydrazides such as luminol in aqueous solutions, J. Am. Chem. Soc. 105 (1983) 7655-7661.

[143] Lohuis J.A., Verheijden J.H., Burvenich C., van Miert A.S., Pathophysiological effects of endotoxins in ruminants. 1. Changes in body temperature and reticulo-rumen motility, and the effect of repeated administration, Vet. Q. 10 (1988) 109-116.

[144] Lohuis J.A., Verheijden J.H., Burvenich C., van Miert A.S., Pathophysiological effects of endotoxins in ruminants. 2. Metabolic aspects, Vet. Q. 10 (1988) 177-125.

[145] Lohuis J.A., Schukken Y.H., Henricks P.A.J., Heyneman R., Burvenich C., Verheijden J.H.M., van Miert A.S.J.P.A.M., Brand A., Preinfection functions of blood polymorphonuclear leukocytes and the outcome of experimental Escherichia coli mastitis, J. Dairy Sci. 73 (1990) 342-350.

[146] Long E., Capuco A.V., Wood D.L., Sonstegard T., Tomita G., Paape M.J., Zhao X., Escherichia coli induces apoptosis and proliferation of mammary cells, Cell Death Differ. 8 (2001) 808-816.

[147] Madsen S.A., Weber P.S., Burton J.L., Altered expression of cellular genes in neutrophils of periparturient dairy cows, Vet. Immunol. Immunopathol. 86 (2002) 159175 .

[148] Magiakou M.A., Mastorakos G., Webster E., Chrousos G.P., The hypothalamic-pituitary-adrenal axis and the female reproduc- tive system, Ann. N. Y. Acad. Sci. 816 (1997) 42-56.

[149] Maloney M.A., Patt H.M., Granulocyte transit from bone marrow to blood, Blood 31 (1968) 195-201.

[150] Mandell G.L., Bactericidal activity of aerobic and anaerobic polymorphonuclear neutrophils, Infect. Immun. 9 (1974) 337-341.

[151] Massart-Leën A.-M., BurvenichC., VandeputteVan Messom G., Hilderson H., Partial prostaglandin-mediated mechanism controlling the release of cortisol in plasma after intravenous administration of endotoxins, Domest. Anim. Endocrinol. 9 (1992) 273-283.

[152] Massart-Leën A.-M., Burvenich C., Massart D.L., Triaglycerol fatty acid composition of milk from periparturient cows during acute Escherichia coli mastitis, J. Dairy Res. 61 (1994) 191-199.

[153] Mayer S.J., Keen P.M., Craven N., Bourn F.J., Regulation of phagolysosome $\mathrm{pH}$ in bovine and human neutrophils: the role of NADPH oxidase activity and an $\mathrm{Na}^{+} / \mathrm{H}^{+}$ant iporter, J. Leuk. Biol. 45 (1989) 239-248.

[154] McDermott C.M., Morrill J.L., Fenwick B.W., Deacylation of endotoxin during natural cases of bovine mastitis, J. Dairy Sci. 74 (1991) 1227-1234.

[155] McRoberts J.A., Riley N.E., Regulation of T84 cell monolayer permeability by insulinlike growth factors, Am. J. Physiol. 262 (1992) C207-C213.

[156] Medzhitov R., Toll-like receptors and innate immunity, Nat. Rev. Immunol. 1 (2001) 135145 .

[157] Mehrzad J., Dosogne H., Meyer E., Burvenich C., Local and systemic effects of endotoxin mastitis on the chemiluminescence of milk and blood neutrophils in dairy cows, Vet. Res. 32 (2001) 131-144.

[158] Mehrzad J., Dosogne H., Meyer E., Heyneman R., Burvenich C., Respiratory burst activity of blood and milk neutrophils in dairy cows during different stages of lactation, J. Dairy Res. 68 (2001) 399-415.

[159] Mehrzad J., Dosogne H., Vangroenweghe F., Burvenich C., A comparative study of bovine blood and milk neutrophils functions with luminol dependent chemiluminescence, Luminescence 16 (2001) 343-356.

[160] Mehrzad J., Respiratory burst activity and viability of bovine blood and milk neutrophils during different stages of lactation and mastitis, Ph.D. thesis, Ghent University, 2002.

[161] Mehrzad J., Duchateau L., Pyörälä S. Burvenich C., Blood and milk neutrophil 
chemiluminescence and viability in primiparous and pluriparous dairy cows during late pregnancy, around parturition and early lactation, J. Dairy Sci. 85 (2002) 3268-3276.

[162] Mena F., Pacheco P., Grosvenor C.E., Effect of electrical stimulation of mammary nerve upon pituitary and plasma prolactin concentrations in anesthetized lactating rats, Endocrinology 106 (1980) 458-452.

[163] Menzies F.D., Bryson D.G., McCallion T., Matthews D.I., A study of mortality among suckler and dairy cows in Northern Ireland in 1992, Vet. Rec. 137 (1995) 531-536.

[164] Metcalf D., The molecular control of cell division, differentiation commitment and maturation in hematopoietic cells, Nature 339 (1989) 27-30.

[165] Miller J.K., Brzezinska-Slebodzinska E., Madsen F.C., Oxidative stress, antioxidants and animal function, J. Dairy Sci. 76 (1993) 2812-2823.

[166] Moncada S., Palmer R.M.J., Higgs E.A., Nitric oxide: physiology, pathophysiology, and pharmacology, Pharmacol. Rev. 43 (1991) 109-142.

[167] Monfardini E., Burvenich C., Massart-Leën A.-M., Smits E., Paape M., Effect of antibiotic induced bacterial clearance in the udder on L-selectin shedding of blood neutrophils in cows with Escherichia coli mastitis, Vet. Immunol. Immunopathol. 67 (1999) 373384.

[168] Monfardini E., Van Merris V., Meyer E., Burvenich C., L-selectin expression increases strongly upon maturation of bovine progenitor cells (abstract), Pflügers Archiv - Eur. J. Physiol. 444 (2002) R4:10.

[169] Munford R.S., Hall C.L., Detoxification of bacterial lipopolysaccharides (endotoxins) by a human neutrophil enzyme, Science 234 (1986) 203-205.

[170] Nelson L., Flock J.-I., Höök M., Lindberg M., Müller H.P., Wadström T., Adhesins in Staphylococcal mastitis as vaccine components, in: Burvenich C., Vandeputte-Van Messom G., Hill A.W. (Eds.), New insights into the pathogenesis of mastitis, Flemish Veterinary Journal, Merelbeke, Belgium, 1991, pp. 111-125.

[171] Newman S.L., Johnston R.B., Role of binding through $\mathrm{C} 3 \mathrm{~b}$ and IgG in polymorphonuclear neutrophil function: studies with trypsin-generated C3b, J. Immunol. 123 (1979) 1839-1846.

[172] Nickerson S.C., Heald C.W., Histopathologic response of the bovine mammary gland to experimentally induced Staphylococcus aureus infection, Am. J. Vet. Res. 42 (1981) 1351-1354.

[173] Ohno N., Morrison D.C., Lipopolysaccharide interaction with lysozyme. Binding of lipopolysaccharide to lysozyme and inhibition of lysozyme enzymatic activity, J. Biol. Chem. 264 (1989) 4434-4441.

[174] Okun D.B., Tanaka K.R., Leukocyte alkaline phosphatase, Am. J. Hematol. 4 (1978) 293-299.

[175] Opdebeeck J.P., Frost A.J., O'Boyle D., Adhesion of Staphylococcus aureus and Escherichia coli to bovine udder epithelial cells, Vet. Microbiol. 16 (1988) 77-86.

[176] Paape M.J., Schultze W.D., Desjardins C., Miller R.H., Plasma corticosteroid, circulating leukocyte and milk somatic cell responses to Escherichia coli endotoxininduced mastitis, Proc. Soc. Exp. Biol. Med. 145 (1974) 553-559.

[177] Paape M.J., Guidry A.J., Jain N.C., Miller R.H., Leukocyte defence mechanisms, in: Burvenich C., Vandeputte-Van Messom G., Hill A.W. (Eds.), New insights into the pathogenesis of mastitis, Flemish Veterinary Journal, Merelbeke, Belgium, 1991, pp. 95109.

[178] Paape M.J., Lillius E., Wiitanen P., Kontio M., Miller R., Intramammary defense against infections induced by Escherichia coli in cows, Am. J. Vet. Res. 57 (1996) 477-482.

[179] Paape M.J., Shafer-Weaver K., Capuco A.V., Van Oostveldt K., Burvenich C., Immune surveillance of mammary tissue by phagocytic cells, Adv. Exp. Med. Biol. 480 (2000) 259-277.

[180] Paape M.J., Mehrzad J., Zhao X., Detilleux J., Burvenich C., Defense of the bovine mammary gland by polymorphonuclear neutrophil leukocytes, J. Mammary Gland Biol. Neoplasia 7 (2002) 109-121.

[181] Paape M.J., Bannerman D.D., Zhao X., Lee J.-W., The bovine neutrophil: structure and function in blood and milk, Vet. Res. 34 (2003) 597-627.

[182] Pacelli R., Wink D.A., Cook J.A., Krishna M.C., DeGraff W., Friedman N., Tsokos M., Samuni A., Mitchell J.B., Nitric oxide potentiates hydrogen peroxide-induced killing of Escherichia coli, J. Exp. Med. 182 (1995) 1469-1479.

[183] Persson K., Sandgren C.H., RodríguezMartínez H., Studies of endotoxin-induced neutrophil migration in bovine teat tissues, using indium-111-labeled neutrophils and biopsies, Am. J. Vet. Res. 53 (1992) 2235 2240 . 
[184] Persson K., Larrson I., Sandgren C.H., Effects of certain inflammatory mediators on bovine neutrophil migration in vivo and in vitro, Vet. Immunol. Immunopathol. 37 (1993) 99-112.

[185] Persson-Waller K., Mammary gland immunology around parturition. Influence of stress, nutrition and genetics, Adv. Exp. Med. Biol. 480 (2000) 231-245.

[186] Peter A.T., Clark P.W., Van Roekel D.E., Luker C.W., Gaines J.D., Bosu W.T., Temporal changes in metabolites of prostanoids in milk of heifers after intramammary infusion of Escherichia coli organisms, Prostaglandins 39 (1990) 451-457.

[187] Piccinini R., Bronzo V., Moroni P., Luzzago P., Zecconi A., Study on the relationship between milk immune factors and Staphylococcus aureus intramammary infections in dairy cows, J. Dairy Res. 66 (1999) 501510.

[188] Pike M.C., Wicha M.S., Yoon P., Mayo L., Boxer L.A., Laminin promotes the oxidative burst in human neutrophils via increased chemoattractant receptor expression, J. Immunol. 142 (1989) 2004-2011.

[189] Powers M.S., White M.E., Dinsmore P., Guard C., Dimock B., Aerobic blood culturing in cows with coliform mastitis, J. Am. Vet. Med. Assoc. 189 (1986) 440-441.

[190] Pyörälä S.H.K., Pyörälä E.O., Efficacy and parenteral administration of three antimicrobial agents in treatment of clinical mastitis in lactating cows: 487 cases (1989-1995), J. Am. Vet. Med. Assoc. 212 (1998) 407-412.

[191] Qu X.D., Harwig S.S., Oren A.M., Shafer W.M., Lehrer R.I., Susceptibility of Neisseria gonorrhoeae to protegrins, Infect. Immun. 64 (1996) 1240-1245.

[192] Raubertas R.F., Shook G.E., Relationship between lactation measures of somatic cell concentration and milk yield, J. Dairy Sci. 65 (1982) 419-425.

[193] Raulo S.M., Sorsa T., Tervahartiala T., Latvanen T., Pirila E., Hirvonen J., Maisi P., Increase in milk metalloproteinase activity and vascular permeability in bovine endotoxin-induced and naturally occurring Escherichia coli mastitis, Vet. Immunol. Immunopathol. 85 (2002) 137-145.

[194] Reeves E.P., Lu H., Jacobs H.L., Messina C.G.M., Bolsover S., Gabella G., Potma E.O., Warley A., Roes J., Segal A.W., Killing activity of neutrophils is mediated through activation of proteases by $\mathrm{K}^{+}$flux, Nature 416 (2002) 291-297.

[195] Riollet C., Rainard P., Poutrel B., Differential induction of complement fragment C5a and inflammatory cytokines during intramammary infections with Escherichia coli and Staphylococcus aureus, Clin. Diagn. Lab. Immunol. 7 (2000) 161-167.

[196] Root R.K., Cohen M.S., The microbicidal mechanisms of human neutrophils and eosinophils, Rev. Infect. Diseases 3 (1981) 565598.

[197] Rosen H., Klebanoff S.J., Chemiluminescence and superoxide production by myeloperoxidase deficient leukocytes, J. Clin. Invest. 58 (1976) 50-60.

[198] Rossi F., The $\mathrm{O}_{2}{ }^{-}$forming NADPH oxidase of the phagocytes: nature, mechanisms of activation and function, Biochem. Biophys. Acta 853 (1986) 65-89.

[199] Rossi F., Zatti M., Changes in the metabolic pattern of polymorphonuclear leukocytes during phagocytosis, Br. J. Exp. Pathol. 45 (1964) 548-559.

[200] Sato N., Asano S., Koeffler H.P., Takaku F., Takatani O., Induction of alkaline phosphatase in neutrophilic granulocytes by natural and recombinant G-CSF, Exp. Hematol 15 (1987) 460-465.

[201] Savill J.S., Wyllie A.H., Henson J.E., Walport M.J., Henson P.M., Haslett C., Macrophage phagocytosis of aging neutrophils in inflammation. Programmed cell death in the neutrophil leads to its recognition by macrophages, J. Clin. Invest. 83 (1989) 865-867.

[202] Scaffidi P., Misteli T., Bianchi M.E., Release of chromatin protein HMGB1 by necrotic cells triggers inflammation, Nature 418 (2002) 191-195.

[203] Schalm O.W., Carroll E.J., Jain N.C., Bovine mastitis, Lea and Febiger, Philadelphia, USA, 1971.

[204] Schalm O.W., Lasmanis J., Cytologic features of bone marrow in normal and mastitic cows, Am. J. Vet. Res. 37 (1976) 359-363.

[205] Schukken Y.H., Grommers F.J., Vande Geer D., Erb H.N., Brand A., Risk factors for clinical mastitis in herds with a low bulk milk somatic cell count. I. Data and risk factors for all cases, J. Dairy Res. 73 (1990) 34633471.

[206] Sears C.L., Kaper J.B., Enteric bacterial toxins: mechanisms of action and linkage to intestinal secretion, Microbiol. Rev. 60 (1996) 167-215

[207] Shafer W.M., Hubalek F., Huang M., Poh J., Bactericidal activity of a synthetic peptide (CG 117-136) of human lysosomal cathepsin $\mathrm{G}$ is dependent on arginine content, Infect. Immun. 64 (1996) 4842-4845 
[208] Shpigel N.Y., Should we use antimicrobials for treatment of coliform mastitis in dairy cows?, Cattle Pract. 6 (1998) 113-116.

[209] Shuster D.E., Kehrli M.E.J., Braumrucker C.R., Relationship of inflammatory cytokines, growth hormone, and insulin-like growth factor-I to reduced performance during infectious disease, Proc. Soc. Exp. Biol. Med. 210 (1995) 140-149.

[210] Shuster D.E., Lee E.K., Kehrli M.E., Bacterial growth, inflammatory cytokine production, and neutrophil recruitment during coliform mastitis in cows within ten days after calving, compared with cows at midlactation, Am. J. Vet. Res. 14 (1996) 1569-1575.

[211] Shuster D.E., Kehrli M.E.J., Rainard P., Paape M., Complement fragment C5a and inflammatory cytokines in neutrophil recruitment during intramammary infection with Escherichia coli, Infect. Immun. 65 (1997) 3286-3292.

[212] Silva I.D., Jain N.C., George L.W., Phagocytic and nitroblue tetrazolium reductive properties of mature and immature neutrophils and eosinophils from blood and bone marrow from cows, Am. J. Vet. Res. 50 (1989) 778-781.

[213] Simms H.H., D'amico R., Studies on polymorphonuclear leukocyte bactericidal function III: the role of extracellular matrix proteins, J. Surg. Res. 72 (1997) 123-128.

[214] Smith K.L., Hogan J.S., Weiss W.P., Dietary vitamin $E$ and selenium affect mastitis and milk quality, J. Anim. Sci. 75 (1997) 16591665.

[215] Smith V.G., Edgerton L.A., Hafs H.D., Convey E.M., Bovine serum estrogens, progestins and glucocorticosteroids during late pregnancy, parturition and early lactation, J. Anim. Sci. 36 (1973) 391-396.

[216] Smits E., Cifrian E., Guidry A.J., Rainard P., Burvenich C., Paape M.J., Cell culture system for studying bovine neutrophil diapedesis, J. Dairy Sci. 79 (1996) 1353-1360.

[217] Smits E., Burvenich C., Guidry A.J., Heyneman R., Massart-Leën A.-M., Diapedesis across mammary epithelium reduces phagocytic and oxidative burst of bovine neutrophils, Vet. Immunol. Immunopathol. 68 (1999) 169-176.

[218] Smits E., Burvenich C., Guidry A.J., Massart-Leën A.-M., Adhesion receptor CD11b/CD18 contributes to neutrophil diapedesis across the bovine blood-milk barrier, Vet. Immunol. Immunopathol. 73 (2000) 255-256

[219] Sordillo L.M., Peel J.E., Effect of interferon$\gamma$ on the production of tumor necrosis factor during acute Escherichia coli mastitis, J. Dairy Sci. 75 (1992) 2119-2125.

[220] Sordillo L.M., Streicher K.L., Mammary gland immunity and mastitis susceptibility, J. Mammary Gland Biol. Neoplasia 7 (2002) $135-146$

[221] Spitznagel J.K., Shafer W.M., Neutrophil killing of bacteria by oxygen-independent mechanisms: A historical summary, Rev. Infect. Dis. 7 (1985) 398-403.

[222] Staudinger B.J., Oberdoerster M.A., Lewis P.J., Rosen H., mRNA expression profiles for Escherichia coli ingested by normal and phagocyte oxidase-deficient human neutrophils, J. Clin. Invest. 110 (2002) 11511163.

[223] Stich R., Shoda L., Dreewes M., Adler B., Jungi T., Brown W., Stimulation of nitric oxide production in macrophages by $\mathrm{Babe}$ sia bovis, Infect. Immun. 66 (1998) 41304136.

[224] Strandberg E., Shook G.E., Genetic and economic responses to breeding programs that consider mastitis, J. Dairy Sci. 72 (1989) 2136-2142.

[225] Styrt B., Species variation in neutrophil biochemistry and function, J. Leuk. Biol. 46 (1989) 63-74.

[226] Suriyasathaporn W., Heuer C., NoordhuizenStassen E.N., Schukken Y.H., Hyperketonemia and the impairment of udder defense: a review, Vet. Res. 31 (2000) 397-412.

[227] Suriyasathaporn W., Schukken Y.H., Nielen M., Brand A., Low somatic cell count: a risk factor for subsequent clinical mastitis in a dairy herd, J. Dairy Sci. 83 (2000) 12481255.

[228] Swain S.D., Nelson L.K., Hanson A.J., Siemsen D.W., Quin M.T., Host defense function in neutrophils from the American bison (Bison bison), Comp. Biochem. Physiol. A Mol. Integr. Physiol. 127 (2000) 137147.

[229] Targowski S.P., Niemialtowski M., Appearance of $\mathrm{Fc}$ receptors on polymorphonuclear leukocytes after migration and their role in phagocytosis, Infect. Immun. 52 (1986) 798-802.

[230] Terranova V.P., DiFlorio R., Hujanen E.S., Lyall R.M., Liotta L.A., Thorgeirsson U., Siegal G.P., Schiffmann E., Laminin promotes rabbit neutrophil motility and attachment, J. Clin. Invest. 77 (1986) 1180-1186.

[231] Terstappen L.W., Safford M., Loken M.R., Flow cytometric analysis of human bone marrow. III. Neutrophil maturation, Leukemia 4 (1990) 657-663. 
[232] Thomas E.L., Jefferson M.M., Grishman M., Myeloperoxidase-catalyzed incorporation of amino acids into proteins: role of hypochlorous acid, and chloramines, Biochemistry 21 (1982) 6299-6308.

[233] Thomas E.L., Fishman M., Oxidation of choloride, and thiocyanate by isolated leukocytes, J. Biol. Chem. 261 (1986) 96949702.

[234] Tolle A., Mastitis - The disease in relation to control methods, IDF-bulletin 85 (1975) 3-15.

[235] Van Den Berg C., de Neeling A.J., Schot C.S., Hustinx W.N., Wemer J., de Wildt D.J., Delayed antibiotic-induced lysis of Escherichia coli in vitro is correlated with enhancement of LPS release, Scand. J. Infect. Dis. 24 (1992) 619-627.

[236] Van Eeden S.F., Miyagashima R., Haley L., Hogg J.C., A possible role for L-selectin in the release of polymorphonuclear leukocytes from bone marrow, Am. J. Physiol. 272 (1997) H1717-H1724.

[237] Van Merris V., Lenjou M., Hoeben D., Nijs G., Van Bockstaele D., Burvenich C., Culture of bovine bone marrow cells in vitro, Vet. Q. 23 (2001) 170-175.

[238] Van Merris V., Meyer E., Dosogne H., Burvenich C., Separation of bovine bone marrow into maturation related myeloid cell fractions, Vet. Immunol. Immunopathol. 83 (2001) 11-17.

[239] Van Merris V., Meyer E., Burvenich C., Functional maturation during bovine granulopoiesis, J. Dairy Sci. 85 (2002) 28592868.

[240] Van Miert A.S., van Duin C.T., Wensing T., Fever and acute phase response induced in dwarf goats by endotoxin and bovine and human recombinant tumour necrosis factor alpha, J. Vet. Pharmacol. Ther. 15 (1992) $332-342$

[241] Van Werven T., Noordhuizen-Stassen E.N., Daemen A.J.J.M., Schukken Y.H., Brand A., Burvenich C., Preinfection in vitro chemotaxis, phagocytosis, oxidative burst, and expression of CD11/CD18 receptors and their predictive capacity on the outcome of mastitis induced in dairy cows with Escherichia coli, J. Dairy Sci. 80 (1997) 67-74.

[242] Van Werven T., Burvenich C., Piens K., van den Broek J., Heyneman R., NoordhuizenStassen E.N., Schukken Y.H., Brand A., Flow cytometric measurement of neutrophil alkaline phosphatase before and during initiation of an induced Escherichia coli mastitis in cattle, Vet. Immunol. Immunopathol. 62 (1998) 235-244.

[243] Van Werven T., Schukken Y., NoordhuizenStassen E., Daeman A., Burvenich C., Brand A., Relationship between metabolic status around parturition and the outcome of an experimentally induced Escherichia coli mastitis in dairy cows, in: The role of leukocytes in bovine Escherichia coli mastitis, $\mathrm{Ph} . \mathrm{D}$. thesis, Utrecht, The Netherlands, 1999, pp. 73-89.

[244] Vandeputte-Van Messom G., Burvenich C., Effect of somatotropin on changes in milk production and composition during coliform mastitis in periparturient cows, J. Dairy Sci. 76 (1993) 3727-3741.

[245] Vandeputte-Van Messom G., Burvenich C., Roets E., Massart-Leën A.-M., Heyneman R., Kremer W.D.J., Brand A., Classification of newly calved cows into moderate and severe responders to experimentally induced Escherichia coli mastitis, J. Dairy Res. 60 (1993) 19-29.

[246] Waage S., Jonsson P., Franklin A., Evaluation of a cow-side test for detection of gramnegative bacteria in milk from cows with mastitis, Acta Vet. Scand. 35 (1994) 207212.

[247] Waage S., Svidland S., Odegaard S.A., Identification of risk factors for clinical mastitis in dairy heifers, J. Dairy Sci. 81 (1998) 1275-1284.

[248] Wachstein M., Alkaline phosphatase activity in normal and abnormal human blood and bone marrow cells, J. Lab. Clin. Med. 32 (1946) 1-7.

[249] Weber L., Peterhans E., Wyler R., The chemiluminescent response of bovine polymorphonuclear leukocytes isolated from milk and blood, Vet. Immunol. Immunopathol. 4 (1983) 397-412.

[250] Weinrauch Y., Drujan D., Shapiro S.D. Weiss J., Zychlinsky A., Neutrophil elastase targets virulence factors of enterobacteria, Nature 417 (2002) 91-94.

[251] Weiss J., Elsbach P., Olsson I., Odeberg H., Purification and characterization of a potent bactericidal and membrane active protein from the granules of human polymorphonuclear leukocytes, J. Biol. Chem. 253 (1978) 2664-2672.

[252] Weiss J., Victor M., Stendhal O., Elsbach P., Killing of gram-negative bacteria by polymorphonuclear leukocytes: role of an $\mathrm{O}_{2}^{-}$ independent bactericidal system, J. Clin. Invest. 69 (1982) 959-970.

[253] Wenz J.R., Barrington G.M., Garry F.B. McSweeny K.D., Dinsmore R.P., Goodell 
G., Callan R.J., Bacteremia associated with naturally occuring acute coliform mastitis in dairy cows, J. Am. Vet. Med. Assoc. 219 (2001) 976-981.

[254] Werling D., Jungi T.W., TOLL-like receptors linking innate and adaptive immune response, Vet. Immunol. Immunopathol. 91 (2003) 1-12.

[255] Whyte M., Renshaw S., Lawson R., Bingle C., Apoptosis and regulation of neutrophil lifespan, Biochem. Soc. Trans. 27 (1999) 802-807.

[256] Williams D.M., Leucocyte alkaline phosphatase as a marker of cell maturity: a quantitative cytochemical and autoradiographic study, Br. J. Hematol. 31 (1975) 371-379.

[257] Worku M., Paape M.J., Filep R., Miller R., Effect of in vitro and in vivo migration of bovine neutrophils on binding and expression of Fc receptors for $\mathrm{IgG}_{2}$ and $\mathrm{IgM}, \mathrm{Am}$. J. Vet. Res. 55 (1994) 221-226.

[258] Yagi Y., Shiono H., Shibahara T., Chikayama Y., Nakamura I., Ohnuma A., Increase in apoptotic polymorphonuclear neutrophils in peripheral blood after intramammary infusion of Escherichia coli lipopolysaccharide, Vet. Immunol. Immunopathol. 89 (2002) 115-125.

[259] Zecconi A., Bronzo V., Piccinini R., Speafico G., Ruffo G., Phagocytic activity of bovine polymorphonuclear neutrophil leukocytes, J. Dairy Res. 61 (1994) 271-279.

[260] Zhang R., Shen Z., Nauseef W.M., Hazen S.L., Defects in leukocyte-mediated initiation of lipid peroxidation in plasma as studied in myeloperoxidase-deficient subjects: systematic identification of multiple endogenous diffusible substrates for myeloperoxidase in plasma, Blood 99 (2002) 1802-1810.

[261] Ziv G., Hartman I., Bogin E., Abidar J., Saran A., Endotoxin in blood and milk of cows during experimental Escherichia coli endotoxin mastitis, Theriogenology 6 (1976) 343-347.

[262] Ziv G., Schultze W.D., Influence of intramammary infusion of polymyxin B on the clinicopathologic course of endotoxin-induced mastitis, Am. J. Vet. Res. 44 (1983) 14461450. 